\title{
Recent Developments of Antimony-Based Anodes for Sodium- and Potassium-Ion Batteries
}

\author{
Bochao Chen ${ }^{1} \cdot$ Ming Liang ${ }^{1} \cdot$ Qingzhao $\mathrm{Wu}^{1} \cdot$ Shan $\mathrm{Zhu}^{2} \cdot$ Naiqin Zhao ${ }^{1,3} \cdot$ Chunnian $\mathrm{He}^{1,2,3,4}$
}

Received: 3 June 2021 / Revised: 9 June 2021 / Accepted: 26 June 2021 / Published online: 24 July 2021

(c) The Author(s) 2021

\begin{abstract}
The development of sodium-ion (SIBs) and potassium-ion batteries (PIBs) has increased rapidly because of the abundant resources and cost-effectiveness of $\mathrm{Na}$ and $\mathrm{K}$. Antimony ( $\mathrm{Sb}$ ) plays an important role in SIBs and PIBs because of its high theoretical capacity, proper working voltage, and low cost. However, Sb-based anodes have the drawbacks of large volume changes and weak charge transfer during the charge and discharge processes, thus leading to poor cycling and rapid capacity decay. To address such drawbacks, many strategies and a variety of Sb-based materials have been developed in recent years. This review systematically introduces the recent research progress of a variety of Sb-based anodes for SIBs and PIBs from the perspective of composition selection, preparation technologies, structural characteristics, and energy storage behaviors. Moreover, corresponding examples are presented to illustrate the advantages or disadvantages of these anodes. Finally, we summarize the challenges of the development of Sb-based materials for $\mathrm{Na} / \mathrm{K}$-ion batteries and propose potential research directions for their further development.
\end{abstract}

Keywords Sodium-ion batteries $\cdot$ Potassium-ion batteries $\cdot$ Sb-based materials $\cdot$ Energy storage

\section{Introduction}

Lithium-ion batteries (LIBs) have penetrated into every aspect of people's life since their commercial application in 1991. Portable electronic devices and electric vehicles are typically powered by LIBs [1, 2]. However, the dramatic rise in the cost of LIBs has risen dramatically due to the uneven distribution of lithium sources, and the explosive growth

Shan Zhu

shanzhu@tju.edu.cn

$\triangle$ Chunnian $\mathrm{He}$

cnhe08@tju.edu.cn

1 School of Materials Science and Engineering, Tianjin Key Laboratory of Composite and Functional Materials, Tianjin University, Tianjin 300072, China

2 Joint School of National University of Singapore and Tianjin University, International Campus of Tianjin University, Binhai New City, Fuzhou 350207, China

3 Collaborative Innovation Center of Chemical Science and Engineering, Tianjin 300072, China

4 Key Laboratory of Advanced Ceramics and Machining Technology, Ministry of Education, Tianjin University, Tianjin 300072, China in demand restricts large-scale energy storage applications in the future [3]. In recent years, sodium-ion (SIBs) and potassium-ion batteries (PIBs) have attracted much attention because they have the same reaction mechanism as LIBs and have the advantages of abundant sodium $(\mathrm{Na})$ and potassium (K) resources (Fig. 1a), low cost, and applicable working voltage [4-6].

To date, few anode materials for SIBs and PIBs can match the status of commercial graphite in LIBs. Therefore, a formidable challenge for the universal application of SIBs and PIBs is to identify and synthesize practical SIB and PIB anode electrode materials with high energy density and long cycle stability. Various types of anode materials for SIBs and PIBs have been studied in detail, such as carbon materials, metals, metal oxides, alloys, sulfides, selenides, and phosphides [7-16]; among them, alloy-based materials, which usually show a higher theoretical capacity by virtue of the alloying reaction mechanism (Fig. 1b), have been extensively studied $[11,15]$. For example, Si-based materials exhibit a relatively high capacity and poor electrical conductivity that limits their inherent advantages. Another type of high capacity material is the phosphorus-based composites; however, they suffer from both the safety issue and an over $440 \%$ volume expansion during operation. By contrast, 
(a)

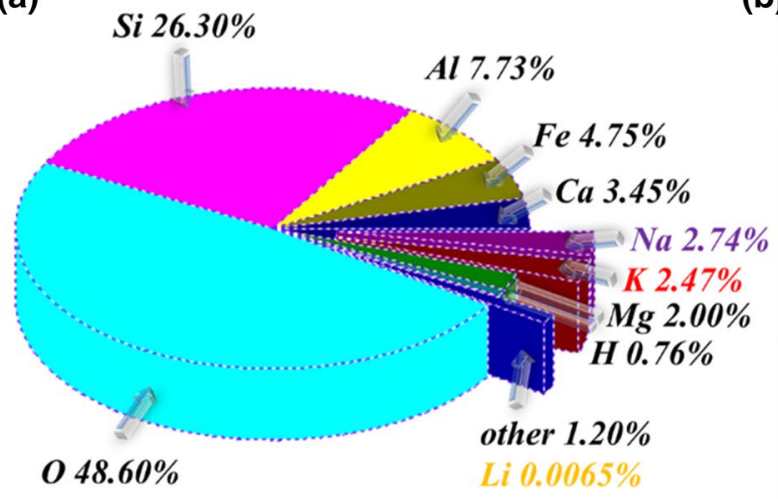

(b)

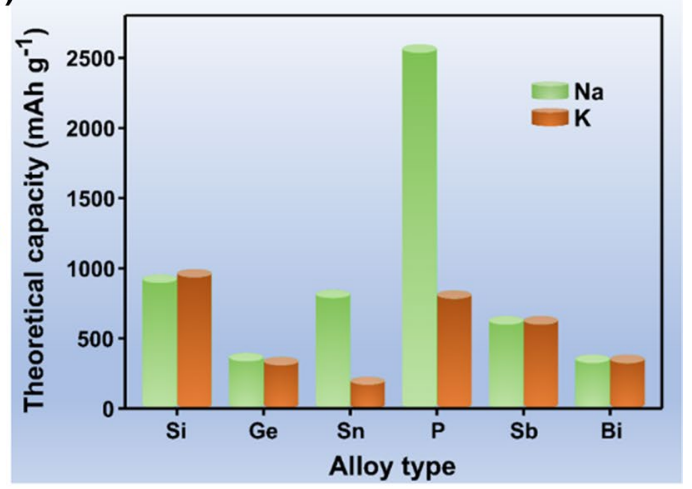

(c)

size reduction, SEl layer thickening, continuous sodium loss

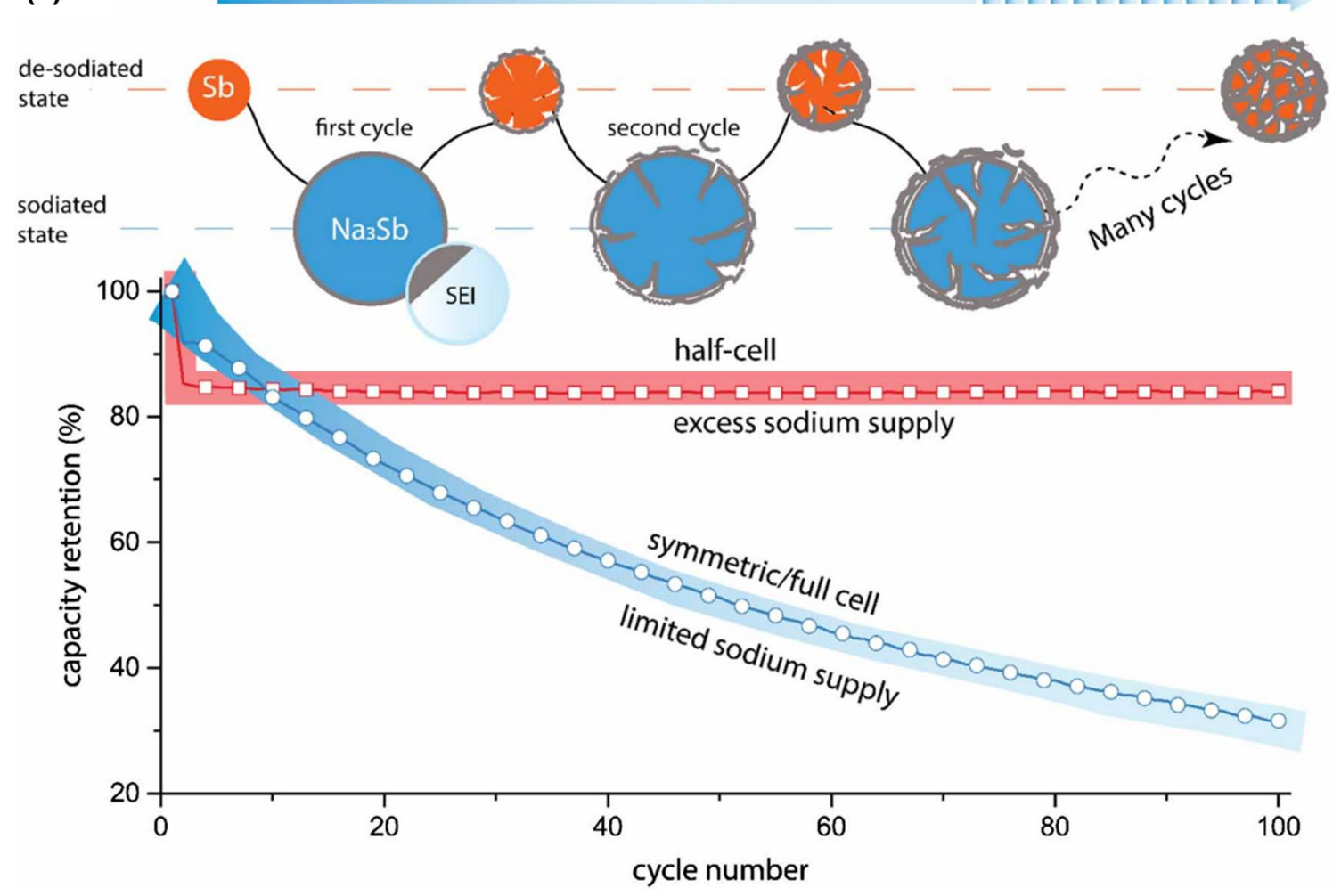

Fig. 1 a Distribution of element content in the earth. b Theoretical capacity of various materials based on alloying reaction mechanism. $\mathbf{c}$ The degradation mechanism of Sb-based anodes in SIBs. Reproduced with permission from Ref. [21]. Copyright 2017, IOP Publishing

antimony ( $\mathrm{Sb}$ ) and Sb-based hybrids have become promising candidates because of their excellent cycle stability, high theoretical capacity in both Na- and K-storage, and low price [17-20]. However, because the failure phenomenon of Sbbased materials is difficult to avoid, researchers must explore new solutions.

The degradation mechanism of Sb-based anodes in SIBs and PIBs can be classified into two aspects: failure of the electrode material and deficiency of the battery system (Fig. 1c). The nature of the material itself is the most important degradation factor. Because of the larger ionic radius of $\mathrm{Na}$ and $\mathrm{K}$, the volume changes of $\mathrm{Sb}$-based materials during SIB/PIB cycling are worse than that in LIBs. Consequently, Sb-based electrodes will face the following failure mechanisms during operation: (1) the volume expansion will cause the material to fall off from the electrode, resulting in loss of active materials and gradual reduction of the capacity that can be used in the operation of the device and (2) the huge volume change (390\% for $\mathrm{Na}, 407 \%$ for $\mathrm{K}$ ) during the charge and discharge processes will lead to the 
pulverization of Sb-based anode and cause the agglomeration of nanoparticles; these phenomena not only slow down the chemical reaction kinetics but also weaken the Coulombic efficiency [17, 20, 21].

In addition to the main factor of material properties, systemic factors, such as electrolyte selection and battery assembly, will cause degradation of the energy storage performance. In the current electrolytes for SIBs and PIBs, many side reactions are prone to occur in the process of storing $\mathrm{Na} / \mathrm{K}$ ions, possibly leading to battery failure [20]. In particular, in a full cell, the parasitic reaction occurring through the SEI layer will irreversibly consume the $\mathrm{Na} / \mathrm{K}$ ions in electrolytes and lead to sharp capacity losses [21].

To overcome the shortcomings of current anodes, a series of Sb-based electrodes in a variety of structures, compositions, and projects were designed and prepared as anodes for SIBs and PIBs. As shown in Fig. 2, the enhancement strategies mainly involve preparing small-sized nanoparticles, compounding with carbon materials, doping with heteroatom dopants, obtaining hierarchical/heterogeneous structure, and constructing yolk-shelled/hollow structure.

Each of these methods has particular advantages and characteristics. The nanoscale particles can directly enhance the reaction kinetics of electrode materials by shortening the pathway of electron diffusion and charge transfer. More importantly, nanoparticles could further alleviate the drastic change of volume during the processes of charge and discharge for SIBs/PIBs. For example, Maksym's group [22] demonstrated that $\mathrm{Sb}$ nanocrystals of around $20 \mathrm{~nm}$ present excellent rate and stable properties when used as the anode

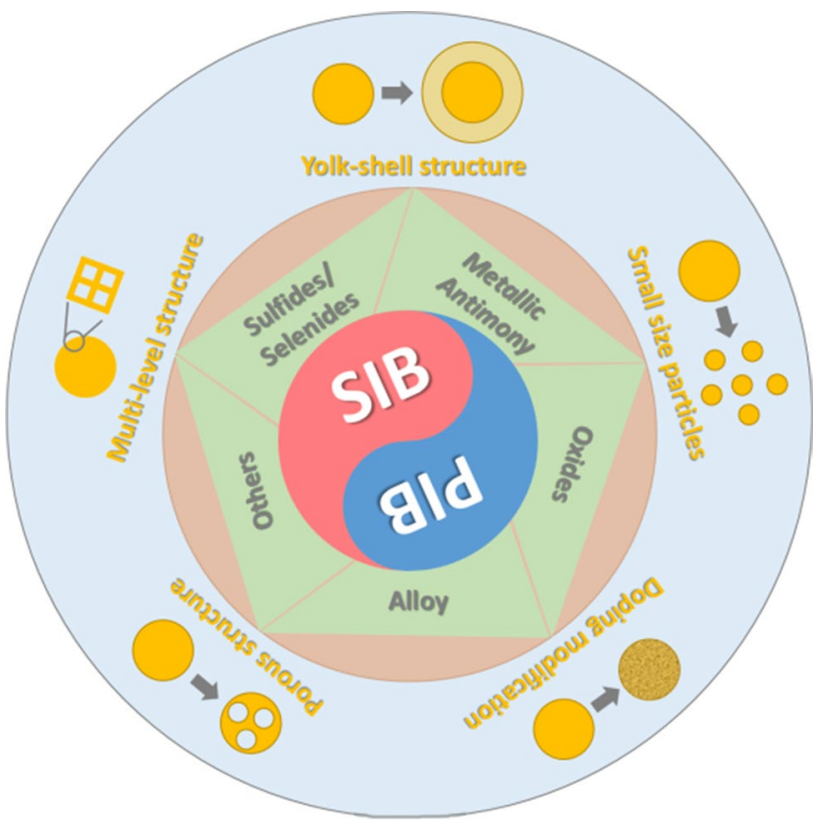

Fig. 2 Species and modification strategies of antimony-based substances studied in SIBs and PIBs material in SIBs. In addition, one of the most widely used methods is to combine a carbon framework with various structures obtained through different synthesis strategies because the carbon skeleton usually plays a dual role in increasing the electrical conductivity of electrode materials and preventing pulverization, thereby maintaining excellent rate activity and cycle stability [16, 23, 24]. For example, Ge and co-workers [25] synthesized ultra-small Sb nanocrystals within carbon nanofibers containing hollow nanochannels (u-Sb@CNFs) through electrospinning; this u-Sb@CNFs complex used as a PIB anode presented a reversible capacity of $225 \mathrm{~mA} \cdot \mathrm{h} / \mathrm{g}$ over 2000 cycles at $1 \mathrm{~A} / \mathrm{g}$. Guo's group [26] reported nanostructured $\mathrm{Sb}$ in an $\mathrm{N}$-doped carbon matrix prepared by a one-step and solvent-free pyrolysis method that displayed high sodium storage and excellent cycle stability. Duan et al. [27] demonstrated a $\mathrm{Sb} / \mathrm{C}_{\mathrm{CHI}}$ nanocomposite synthesized by self-wrapping and controlled growth process that possessed a reversible capacity of $403 \mathrm{~mA} \cdot \mathrm{h} / \mathrm{g}$ at $250 \mathrm{~mA} / \mathrm{g}$, an excellent rate capability $(138 \mathrm{~mA} \bullet \mathrm{h} / \mathrm{g}$ at 32 $\mathrm{A} / \mathrm{g}$ ), and good cycle stability. In order to further improve the conductivity of the carbon framework, enhance the charge and ion transfer speed, and boost the amount of sodium/ potassium storage, the patterns of heteroatom doping have become the focus of attention. Nitrogen $(\mathrm{N})$, sulfur $(\mathrm{S})$, and phosphorus $(\mathrm{P})$ are the most frequently doped atoms, with $\mathrm{N}$ and $\mathrm{S}$ being the most widely used heteroatom dopants [28-30]. However, P doping is rarely reported in Sb-based materials because of the safety hazards involved with the $P$ species and technical difficulties. Chen and Tuan [31] prepared phosphorus-embedded ultra-small BiSb nanocrystals through solution precipitation and used the material as a PIB anode electrode; the composite material exhibited excellent cycle stability $(339.1 \mathrm{~mA} \cdot \mathrm{h} / \mathrm{g}$ at $1 \mathrm{~A} / \mathrm{g}$ after 550 cycles) and outstanding rate performance $(258.5 \mathrm{~mA} \cdot \mathrm{h} / \mathrm{g}$ at $6.5 \mathrm{~A} / \mathrm{g})$. Dong and co-workers [32] constructed porous phosphosulfide nanospheres combined with ultra-small Sb nanoparticles pinned into 3D macroporous carbon foam ( $\mathrm{Sb} \mid \mathrm{P}-\mathrm{S} @ \mathrm{C}$ ) that displayed reversible capacities of $490 \mathrm{~mA} \cdot \mathrm{h} / \mathrm{g}$ at $0.1 \mathrm{~A} / \mathrm{g}$ over 1000 cycles when used as an SIB anode. Both S and $\mathrm{P}$ are electrochemically active elements that can react with sodium and potassium; this reaction can not only improve the conductivity but also provide additional capacity when combined with the matrix carbon material $[8,33,34]$. In this regard, the composite of P-doped carbon framework and Sbbased materials should receive increasing attention and be developed vigorously. Compared with the above-mentioned improved system, generally, the carbon architecture (such as multi-level structure, yolk-shelled structure, and hollow structure) plays a more significant role in enhancing the storage capacity of $\mathrm{Na}$ and $\mathrm{K}$.

In this review, we focus on the use of Sb-based materials as the anodes of SIBs and PIBs. Specifically, Sb-based materials will be analyzed according to their respective 
composition, including metallic $\mathrm{Sb}, \mathrm{Sb}$ oxides, $\mathrm{Sb}$ sulfides, and $\mathrm{Sb}$ alloys. For each part, we will define the problems faced by Sb-based materials in this category and introduce researchers' measures to solve specific problems, such as introducing carbon protection and constructing special structures. Consequently, the effectiveness of these measures will be discussed, and the corresponding energy storage performance will be reviewed. Finally, the current opportunities and challenges of Sb-based material will be listed to provide guidance for future research on Sb-based electrode materials.

\section{Sodium-Ion Batteries}

\section{Metallic Antimony for Sodium-Ion Batteries}

Recently, the sodium storage mechanisms of Sb-based materials have been introduced in detail in previous reports. Briefly, metal $\mathrm{Sb}$ and sodium can contribute up to a theoretical capacity of $660 \mathrm{~mA} \cdot \mathrm{h} / \mathrm{g}$, depending on the alloying/ dealloying reaction $\left(\mathrm{Sb}+3 \mathrm{Na}^{+}+3 \mathrm{e}^{-} \leftrightarrow \mathrm{Na}_{3} \mathrm{Sb}\right)[11,16-18$, 20]. However, the volume of Sb changes sharply (around $390 \%$ ) during the $\mathrm{Na}^{+}$charge and discharge processes, causing the electrode material to be crushed and fall from the current collector, resulting in irreversible capacity decline. In addition, $\mathrm{Sb}$ reduces the performance in sodium storage owing to the poor conductivity, especially the rate capacity $[35,36]$. In the process of overcoming the above conundrums, special structures prepared by multi-directional synthesis strategies often play a key role. In the structure of metal Sb regard [37], Yang et al. [38] used a hybrid of amorphous $\mathrm{Sb} / \mathrm{N}$-doped layered carbon as a SIB anode and obtained remarkable stability $(280.5 \mathrm{~mA} \bullet \mathrm{h} / \mathrm{g}$ over 500 cycles at $1 \mathrm{~A} / \mathrm{g}$ ) and excellent rate capability (479.6 and $298.7 \mathrm{~mA} \cdot \mathrm{h} / \mathrm{g}$ at current density of 0.1 and $2 \mathrm{~A} / \mathrm{g}$, respectively). Starting from the structure of Sb itself, Tian et al. [39] reported that two-dimensional (2D) few-layer Sb has the highest theoretical capacity utilization, as indicated by the highest capacity $(642 \mathrm{~mA} \cdot \mathrm{h} / \mathrm{g}$ at $66 \mathrm{~mA} / \mathrm{g})$ among many $\mathrm{Sb}$ materials and the capacity to hold $620 \mathrm{~mA} \bullet \mathrm{h} / \mathrm{g}$ at $330 \mathrm{~mA} / \mathrm{g}$ over 150 cycles. It can be seen that 2D materials and 2D carbon framework modification methods are effective in facilitating Na storage because of the rapid migration of electrons and charges on the 2D layered substance surface.

The different configurations of Sb-carbon hybrids will further affect the Na storage ability of the electrode. In particular, the use of a yolk-shelled structure has been recognized as one of the most effective methods to adjust volume expansion and thus improve the cycle stability of materials [40-42]. As displayed in Fig. 3a, b, Song et al. [43] prepared yolk-shelled structure Sb@C anodes by virtue of a controlled reduction and selective removal method and found that the anodes delivered a high rate capability $(554 \mathrm{~mA} \cdot \mathrm{h} / \mathrm{g}$ at $50 \mathrm{~mA} / \mathrm{g}$ and $315 \mathrm{~mA} \cdot \mathrm{h} / \mathrm{g}$ at $6.6 \mathrm{~A} / \mathrm{g}$ ) and $92 \%$ capacity retention over 200 cycles (Fig. 3c). The yolkshelled structure accommodates the volume expansion of $\mathrm{Sb}$ during sodium insertion and thus prevents the electrode structure from being damaged. Also, in situ TEM characterization was employed to prove that the yolk-shelled structure can effectively avoid the collapse of the structure during the $\mathrm{Na}^{+}$embedded process, thereby ensuring the cycle stability (Fig. 3d). To conduct a full cell investigation, the $\mathrm{O}_{3}-\mathrm{Na}_{0.9}\left[\mathrm{Cu}_{0.22} \mathrm{Fe}_{0.30} \mathrm{Mn}_{0.48}\right] \mathrm{O}_{2}$ was chosen as the cathode. The electrochemical test showed that the voltage range of the full cell is $2.0-4.0 \mathrm{~V}$ and the specific energy was calculated to be $130 \mathrm{~W} \cdot \mathrm{h} / \mathrm{kg}$. In addition, Mai's group [44] synthesized $\mathrm{Sb} @ \mathrm{~N}-\mathrm{C}$ with a nanorod-in-nanotube structure by way of a bottom-up confinement pathway. The structure is of an approximate yolk-shelled structure, which can relieve the internal stress generated by metal $\mathrm{Sb}$ during the charge and discharge processes, further improving the cycle stability. Moreover, the N-doped carbon nanotube can effectively improve ion transport, thus resulting in excellent rate performance. As a result, $\mathrm{Sb} @ \mathrm{~N}-\mathrm{C}$ showed an excellent high rate $(309.8 \mathrm{~mA} \cdot \mathrm{h} / \mathrm{g}$ at $10 \mathrm{~A} / \mathrm{g})$ and the cycle stability of up to $345.6 \mathrm{~mA} \bullet \mathrm{h} / \mathrm{g}$ after 3000 cycles at $2 \mathrm{~A} / \mathrm{g}$ for Na storage.

Recently, our group [45] proposed a one-pot strategy for the synthesis of porous microsphere composite materials surrounded by N/S co-doped carbon nanosheets wrapped with yolk-shelled Sb. Because of the interaction of the strong yolk-shelled structure and the N/S co-doped porous microspheres, the obtained material has achieved a cycle stability of $331 \mathrm{~mA} \cdot \mathrm{h} / \mathrm{g}$ after 10,000 cycles at $20 \mathrm{~A} / \mathrm{g}$. Note that the synthesis strategy is suitable for large-scale preparation and provides a reference for commercial applications. More importantly, the yolk-shelled architecture can effectively maintain the structural integrity of electrode materials and improve cycle stability during the repeated charge and discharge processes. In short, the use of the yolk-shelled structure is a promising method to boost the Na storage performance of a Sb-based material.

The hollow structure is one of the most suitable architectures that can improve the Na storage behavior of electrode materials, which has a positive effect on Sb species [46, 47]. As presented in Fig. 4a, Liu et al. [48] discovered that Sn and $\mathrm{Sb}$ can exchange ions $\left(3 \mathrm{Sn}+4 \mathrm{Sb}^{3+} \rightarrow 3 \mathrm{Sn}^{4+}+4 \mathrm{Sb}\right)$ and that the hollow $\mathrm{Sb}$ spheres can be formed and completely coated by carbon shell during the ion exchange process. There are many void spaces in the hollow sphere that can fully accommodate the volume change of Sb during charging and discharging. A compact solid electrolyte interface will form at the outer layer of the hollow sphere. Finally, the hollow $\mathrm{Sb} @ \mathrm{C}$ used as an anode for SIBs displayed high rate capability at $2 \mathrm{~A} / \mathrm{g}$ and maintained a capacity of $\sim 280 \mathrm{~mA} \bullet \mathrm{h} / \mathrm{g}$ over 200 cycles at $1 \mathrm{~A} / \mathrm{g}$ (Fig. 4b). Liu and co-workers [49] 
(a)
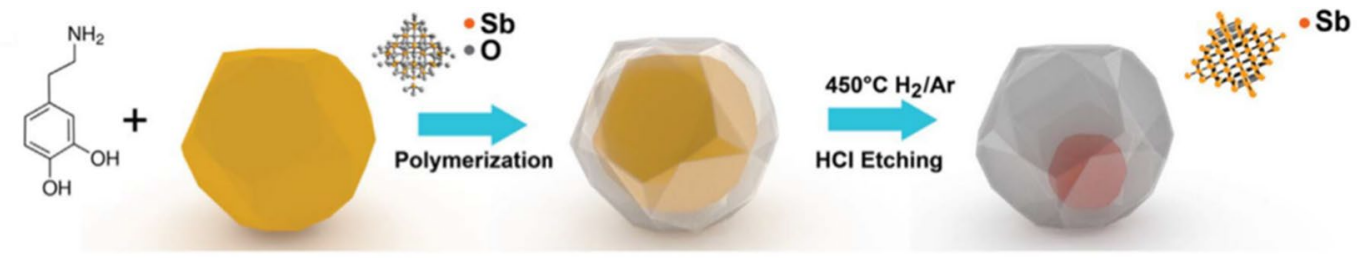

Dopamine

$\mathrm{Sb}_{2} \mathrm{O}_{3}$

$\mathrm{Sb}_{2} \mathrm{O}_{3} @ P D A$

Sb@C

(b)

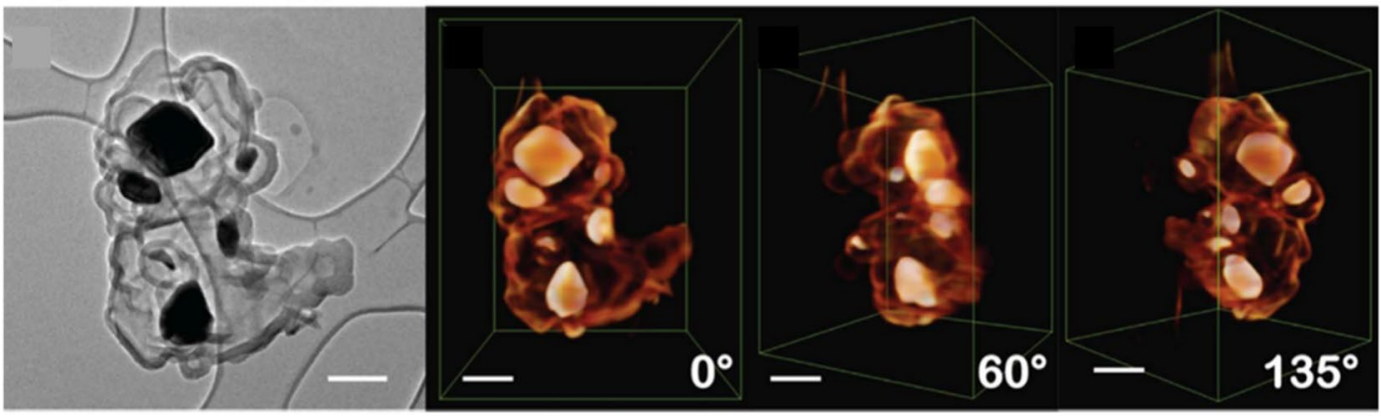

(c)

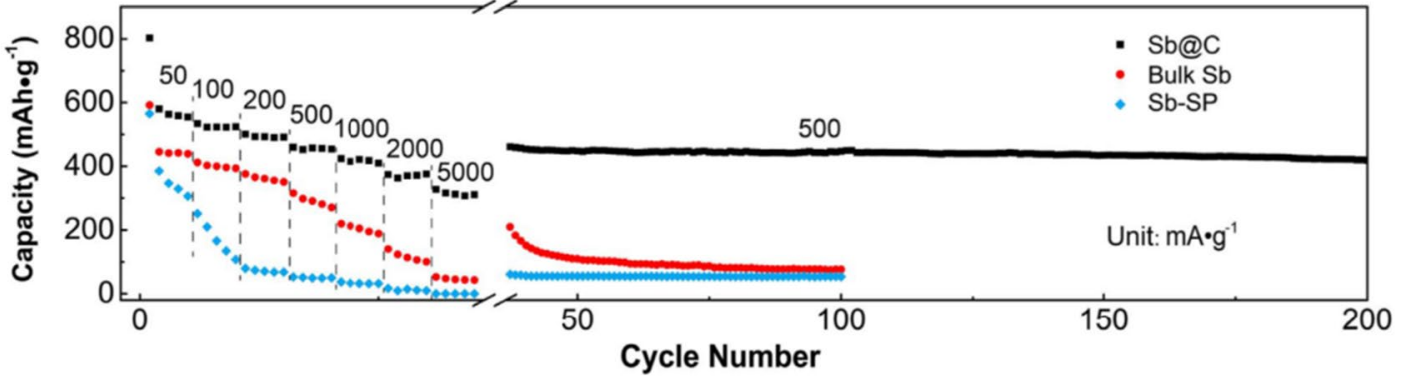

(d)
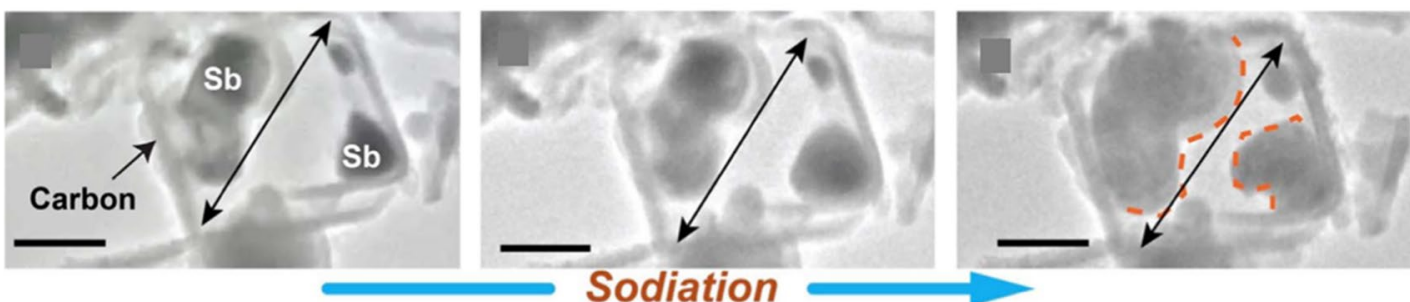

Fig. 3 a Formation process of embedded Sb yolk-shelled structure by controlled reduction and selective removal, $\mathbf{b}$ TEM image and screenshots of the 3D reconstruction of Sb@C yolk-shelled structure, $\mathbf{c}$ the corresponding rate and cycle performance of $\mathrm{Sb} @ \mathrm{C}$ yolk-shelled

structure, $\mathbf{d}$ in situ TEM images of Sb@C yolk-shelled structure upon sodiation. Reproduced with permission from Ref. [43]. Copyright 2017, Elsevier

synthesized unique $\mathrm{Sb} @ \mathrm{C}$ coaxial nanotubes via carbon reduction $\mathrm{Sb}_{2} \mathrm{~S}_{3}$. These coaxial nanotubes have a hollow-like structure and can achieve high electron/charge dynamics and structural integrity. As a SIB anode, the composite delivered a reversible capacity of $350 \mathrm{~mA} \cdot \mathrm{h} / \mathrm{g}$ and $310 \mathrm{~mA} \cdot \mathrm{h} / \mathrm{g}$ at 10 and $20 \mathrm{~A} / \mathrm{g}$, respectively, and maintained a specific capacity of $240 \mathrm{~mA} \bullet \mathrm{h} / \mathrm{g}$ over 2000 cycles at $1 \mathrm{~A} / \mathrm{g}$. As a recyclable template strategy for making pores and hollow skeletons, salt template technology has been used in LIBs and SIBs [45, 50, 51]. $\mathrm{Xu}$ et al. [52] employed the $\mathrm{KCl}$ template to prepare $\mathrm{Sb}$ HPs@OCB with hollow Sb nanoparticles encapsulated in a carbon box (Fig. 4c). The hollow nanoparticle architecture can significantly enhance the kinetics of the sodium storage reaction. Ultimately, the Sb HPs@OCB composite displayed

an excellent rate capability of $345 \mathrm{~mA} \cdot \mathrm{h} / \mathrm{g}$ at $16 \mathrm{~A} / \mathrm{g}$ and a specific capacity of $187 \mathrm{~mA} \cdot \mathrm{h} / \mathrm{g}$ over 300 cycles at $10 \mathrm{~A} / \mathrm{g}$ under $50 \mathrm{C}$. Evidently, the hollow structures obtained via various synthesis strategies often exhibit excellent rate and cycle stability. However, methods to improve the first-cycle Coulombic efficiency and increase the vibration density should also be studied.

In addition to using carbon to coat $\mathrm{Sb}$ for enhancing the performance of sodium storage, compositing $\mathrm{Sb}$ with other stable materials in the charge and discharge processes is another effective approach [41]. For example, Kong and co-workers [53] synthesized $\mathrm{Sb} @ \mathrm{C} @ \mathrm{TiO}_{2}$ triple-shell nano-boxes via a template-engaged galvanic replacement approach. As expected, the anode exhibited excellent rate 

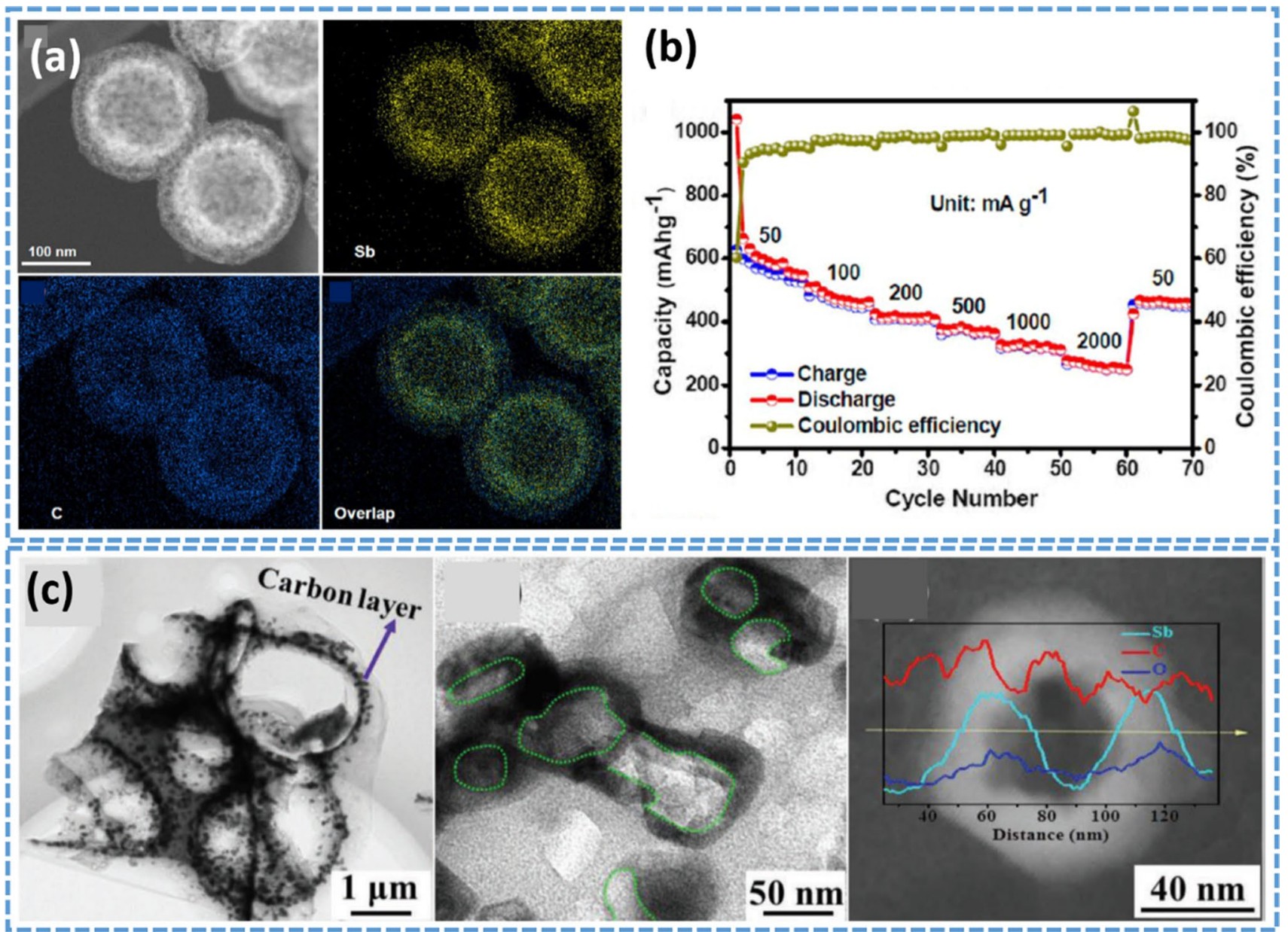

Fig. 4 a EDS mapping of hollow Sb spheres, $\mathbf{b}$ rate capability of hollow Sb spheres. Reproduced with permission from Ref. [48]. Copyright 2017, American Chemical Society. c TEM images of Sb HPs@

performance and ultra-long cycle stability $(193 \mathrm{~mA} \cdot \mathrm{h} / \mathrm{g}$ over 4000 cycles at $1 \mathrm{~A} / \mathrm{g}$ ), relying on the $\mathrm{TiO}_{2}$-shell in SIBs. In a similar manner, Lee et al. [54] prepared Sb-embedded silicon oxycarbide composites via a one-pot pyrolysis process (Fig. 5a). Because of the free-carbon domain of the silicon-oxygen-carbon framework and uniform distribution of embedded $\mathrm{Sb}$ nanoparticles, the conductivity is improved and the agglomeration of $\mathrm{Sb}$ during the reaction process is inhibited in the SIB anode. Unsurprisingly, the composite materials kept a capacity retention rate of $\sim 97 \%$ over 250 cycles and exhibit $510 \mathrm{~mA} \bullet \mathrm{h} / \mathrm{g}$ and $453 \mathrm{~mA} \bullet \mathrm{h} / \mathrm{g}$ at $0.1 \mathrm{C}$ and $20 \mathrm{C}$ rate, respectively (Fig. $5 \mathrm{~b}, \mathrm{c}$ ). At the same time, the capacity of the sample did not decrease significantly after 100 cycles at $0.5,1$, and $2 \mathrm{C}$ (Fig. 5d). Therefore, the influence of the non-pure carbon matrix should be valued for $\mathrm{Na}$ storage in the future.

In an alternative approach, the heteroatom dopants inside of carbon can effectively improve the ion transport kinetics and electron diffusion ability of $\mathrm{Sb}$ active materials, thereby
OCB. Reproduced with permission from Ref. [52]. Copyright 2019, John Wiley \& Sons, Inc

providing the possibility to obtain a high rate performance SIB anode [55-57]. As revealed in Fig. 6a, Cui and coworkers [58] fabricated composite hybrids of $\mathrm{Sb}$ nanorods encapsulated in an $\mathrm{N}$ and $\mathrm{S}$ co-doped carbon skeleton. The $\mathrm{N}$ and $\mathrm{S}$ dopants in the carbon framework contribute to the enhancement of charge and electron mobility. Therefore, the composite displayed high reversible capacities and long-term cycle stability $(621.1 \mathrm{~mA} \cdot \mathrm{h} / \mathrm{g}$ at $100 \mathrm{~mA} / \mathrm{g}$ after 150 cycles and $390.8 \mathrm{~mA} \bullet \mathrm{h} / \mathrm{g}$ at $1 \mathrm{~A} / \mathrm{g}$ after 1000 cycles) for a SIB anode. In addition, the hierarchical structure can achieve superb $\mathrm{Na}$ storage vitality as an anode for metal $\mathrm{Sb}$ materials because of the large specific surface area and the synergy between different types of structures. For instance, $\mathrm{Yu}$ et al. [59] reported a strategy that enabled the tiny $\mathrm{Sb}$ nanoparticles to be fully embedded in MOF-derived carbon and $\mathrm{TiO}_{2}$ nanotubes. The obtained $\mathrm{Sb} \subset \mathrm{CTHN}$ s presented enhanced stability when used as a Na-ion battery anode. Using $\mathrm{Na}_{3} \mathrm{~V}_{2}\left(\mathrm{PO}_{4}\right)_{3}$ as the cathode, a full cell was assembled to examine the practical performances of Sb $\subset$ CTHNs. 

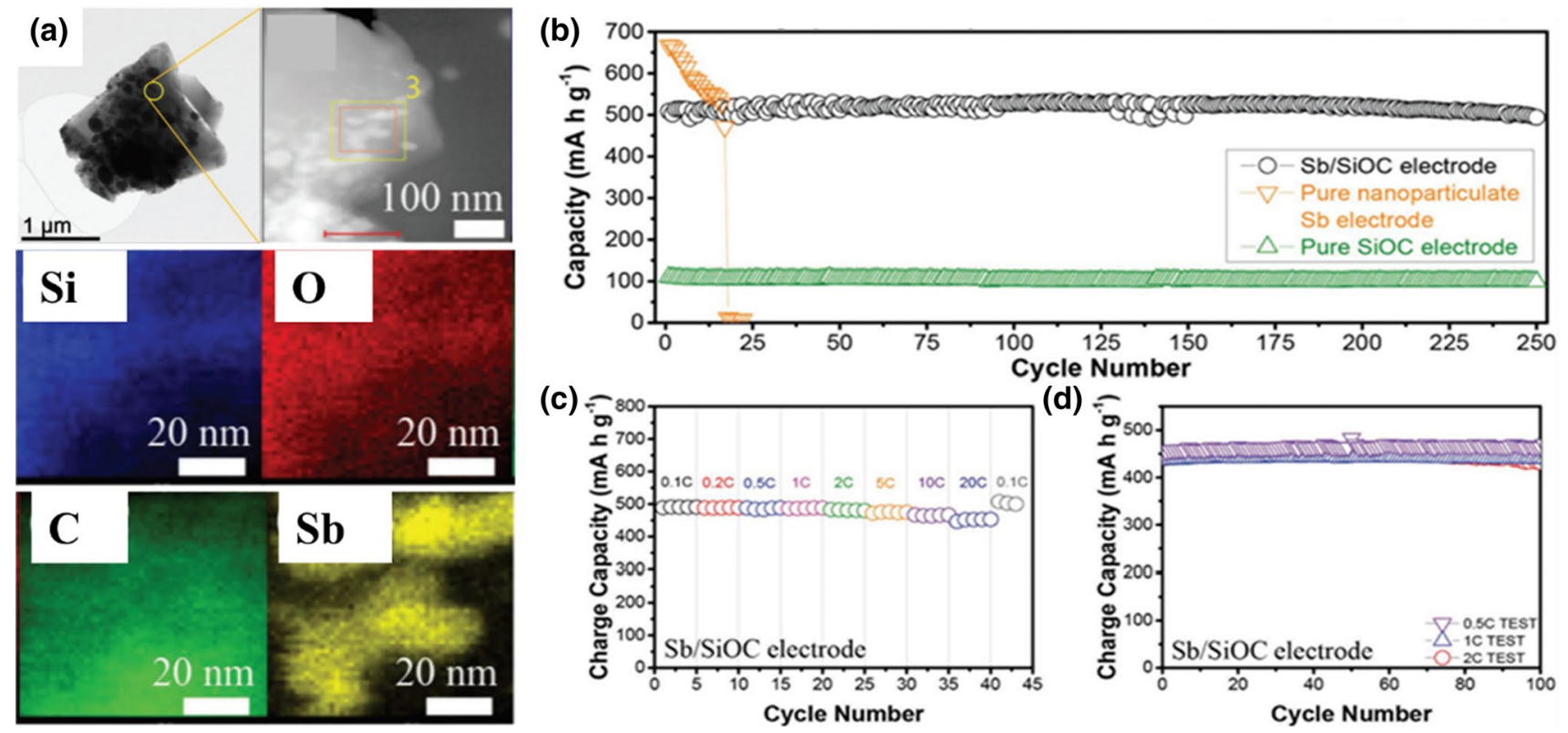

(d)

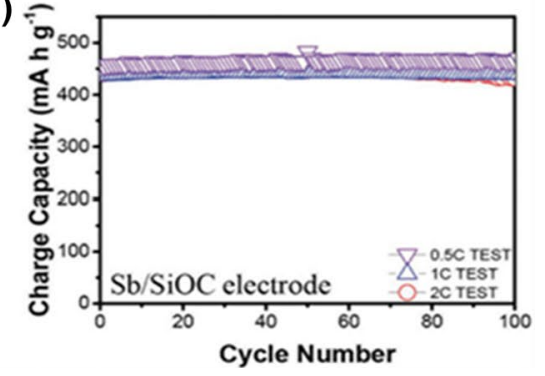

Fig. 5 a TEM images and EDS mapping of Sb-embedded silicon oxycarbide (SiOC) composites, b the corresponding cycle performance of Sb-embedded SiOC composites between 0.001 and $2 \mathrm{~V}$, c rate capability of $\mathrm{Sb}$-embedded $\mathrm{SiOC}$ electrode materials, $\mathbf{d}$ cycling

This cell displayed two charge and discharge plateaus at $2.45 \mathrm{~V}$ and $2.65 \mathrm{~V}$ and achieved a reversible capacity of $497.7 \mathrm{~mA} \bullet \mathrm{h} / \mathrm{g}$ after 100 cycles. The reason for such stability could be the limitation of the volume expansion of Sb by the carbon and $\mathrm{TiO}_{2}$ walls. In addition, as shown in Fig. 6b, Fan et al. [60] constructed a core-shelled Cu@Sb nanowire array anchored on 3D porous $\mathrm{Cu}$ foam through anodization and high-temperature reduction. The hierarchical 3D structure with interconnected pores and voids between nanowires can effectively relieve the internal stress and promote the consistent transport of electrons and ions along the growth direction of the nanowire during charging and discharging. As a result, this core-shelled structure delivered a capacity of $605.3 \mathrm{~mA} \bullet \mathrm{h} / \mathrm{g}$ at $330 \mathrm{~mA} / \mathrm{g}$ and demonstrated a capacity retention rate of $84.8 \%$ at $3.3 \mathrm{~A} / \mathrm{g}$ after 200 cycles as an anode for SIBs. Li et al. [61] proposed a self-supported $\mathrm{Sb}$ prism array that was directly grown on a $\mathrm{Cu}$ substrate by way of a template-free electrodeposition (Fig. 6c). Similar to the above-mentioned Cu@Sb nanowires array, the $\mathrm{Sb}$ prism array, by virtue of the hierarchical construction, had enough space between each other to adjust the internal stress generated during the sodium storage process and thus improve the cycle stability. Ultimately, the $\mathrm{Sb}$ array kept $531 \mathrm{~mA} \bullet \mathrm{h} / \mathrm{g}$ and $492 \mathrm{~mA} \bullet \mathrm{h} / \mathrm{g}$ over 100 cycles at $0.5 \mathrm{C}$ and $1 \mathrm{C}$, respectively (Fig. 6d). Attractively, heteroatom doping and ingenious hierarchical structure design can bring excellent sodium storage properties for $\mathrm{Sb}$. In particular, the idea can be extended to other Sb-based materials. performance of $\mathrm{Sb}$-embedded $\mathrm{SiOC}$ electrode materials at a current density of $0.5,1$, and $2 \mathrm{C}$, respectively. Reproduced with permission from Ref. [54]. Copyright 2017, John Wiley \& Sons, Inc

In order to better highlight and compare the electrochemical performance of the metal Sb-based materials, we summarize the reported electrochemical performance of metal $\mathrm{Sb}$ as the anode of SIBs in Table 1. A variety of nano- or microstructural and morphology designs allow metal $\mathrm{Sb}$ to exhibit excellent rate performance and cycle stability [62-74]. These innovative studies not only establish an effective electrode configuration for the future exploration of metal $\mathrm{Sb}$ but also provide a wealth of reference materials for the rational design of other Sb-based materials.

\section{Antimony Oxides for Sodium-Ion Batteries}

Antimony oxide mainly contains $\mathrm{Sb}_{2} \mathrm{O}_{3}$ and $\mathrm{Sb}_{2} \mathrm{O}_{4}$, for which the theoretical capacity of the anode is $1102 \mathrm{~mA} \bullet \mathrm{h} / \mathrm{g}$ and $1120 \mathrm{~mA} \bullet \mathrm{h} / \mathrm{g}$ in SIBs, respectively. In comparison with $\mathrm{Sb}_{2} \mathrm{O}_{4}, \mathrm{Sb}_{2} \mathrm{O}_{3}$ has been studied more because it is an easily synthesized $\mathrm{Sb}$-based oxide material via the simple lower temperature heat treatment. The process of storing sodium by antimony oxide can be summarized as follows [17, 75]:

$\mathrm{Sb}_{2} \mathrm{O}_{3}+6 \mathrm{Na}^{+}+6 \mathrm{e}^{-} \leftrightarrow 2 \mathrm{Sb}+3 \mathrm{Na}_{2} \mathrm{O}\left(\mathrm{Sb}_{2} \mathrm{O}_{3}\right.$ : conversion reaction $)$

$2 \mathrm{Sb}+6 \mathrm{Na}^{+}+6 \mathrm{e}^{-} \leftrightarrow 2 \mathrm{Na}_{3} \mathrm{Sb}\left(\mathrm{Sb}_{2} \mathrm{O}_{3}\right.$ : alloying reaction $)$

$\mathrm{Sb}_{2} \mathrm{O}_{4}+8 \mathrm{Na}^{+}+8 \mathrm{e}^{-} \leftrightarrow 2 \mathrm{Sb}+4 \mathrm{Na}_{2} \mathrm{O}\left(\mathrm{Sb}_{2} \mathrm{O}_{4}\right.$ : conversion reaction $)$ 


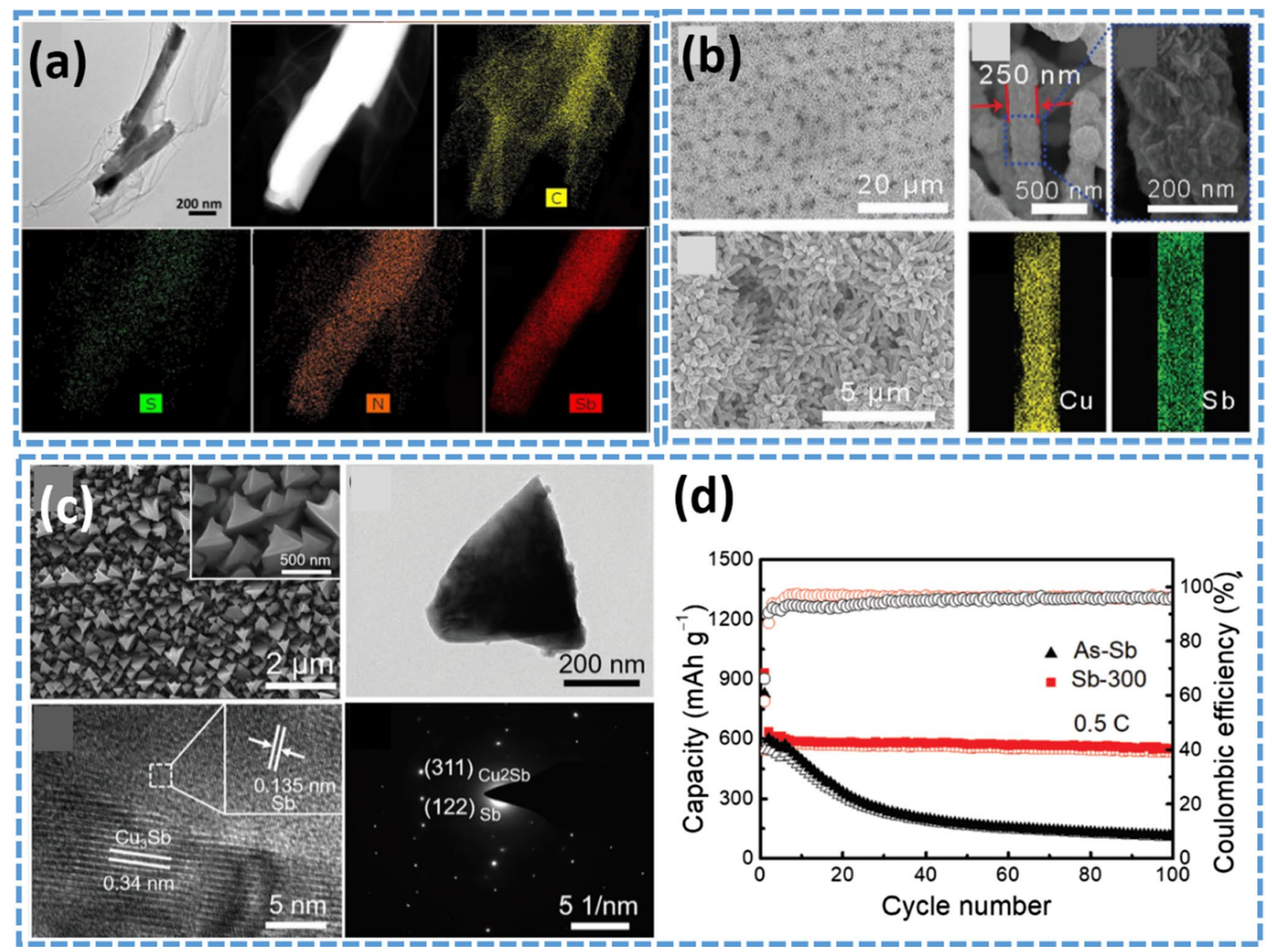

Fig. 6 a TEM images and EDS mapping of composite materials of $\mathrm{Sb}$ nanorods encapsulated in N/S co-doped carbon framework. Reproduced with permission from Ref. [58]. Copyright 2019, American Chemical Society. b SEM and TEM images and EDS mapping of core-shelled $\mathrm{Cu} @ \mathrm{Sb}$ nanowires array. Reproduced with permis-

$2 \mathrm{Sb}+6 \mathrm{Na}^{+}+6 \mathrm{e}^{-} \leftrightarrow 2 \mathrm{Na}_{3} \mathrm{Sb}\left(\mathrm{Sb}_{2} \mathrm{O}_{4}:\right.$ alloying reaction $)$

However, extensive research studies and practical applications of $\mathrm{Sb}_{2} \mathrm{O}_{3} / \mathrm{Sb}_{2} \mathrm{O}_{4}$ as an anode for $\mathrm{SIBs}$ are limited because of their poor conductivity. For this reason, $\mathrm{Sb}_{2} \mathrm{O}_{3} / \mathrm{Sb}_{2} \mathrm{O}_{4}$ and materials with excellent conductivity are combined into composites to produce the electrode of SIBs [76-78], with compounding with carbon materials being the most common and effective strategy [79, 80]. As revealed in Fig. 7a, Wang et al. [81] prepared $\mathrm{Sb}_{2} \mathrm{O}_{4} /$ $\mathrm{RGO}$ with $\mathrm{Sb}_{2} \mathrm{O}_{4}$ nanorods anchored on reduced graphene oxide. With the aid of reduced graphene oxide, the rod-like $\mathrm{Sb}_{2} \mathrm{O}_{4}$ showed a reversible capacity of $\sim 551 \mathrm{~mA} \bullet \mathrm{h} / \mathrm{g}$ over 100 cycles at $50 \mathrm{~mA} / \mathrm{g}$ (Fig. 7b) and obtained a rate performance of $401 \mathrm{~mA} \bullet \mathrm{h} / \mathrm{g}$ at $1 \mathrm{~A} / \mathrm{g}$. In another strategy, Guo and co-workers [82] fabricated $\mathrm{Sb}_{2} \mathrm{O}_{3} / \mathrm{MXene}\left(\mathrm{Ti}_{3} \mathrm{C}_{2} \mathrm{~T}_{x}\right)$ sion from Ref. [60]. Copyright 2019, John Wiley \& Sons, Inc. c SEM and TEM images of self-supported $\mathrm{Sb}$ prisms array directly grown on a $\mathrm{Cu}$ substrate, $\mathbf{d}$ the corresponding cycle performance of self-supported $\mathrm{Sb}$ prisms array at $0.5 \mathrm{C}$. Reproduced with permission from Ref. [61]. Copyright 2019, John Wiley \& Sons, Inc

hybrid materials via a facile solution-phase project. The MXene has two functions: (1) the highly conductive MXene can provide an efficient transport path for ions and electrons; (2) the 2D sheet spacing configuration can effectively release the internal stress generated during the sodium storage process. Therefore, the $\mathrm{Sb}_{2} \mathrm{O}_{3} / \mathrm{Ti}_{3} \mathrm{C}_{2} \mathrm{~T}$. presented a rate capacity of $295 \mathrm{~mA} \bullet \mathrm{h} / \mathrm{g}$ at $2 \mathrm{~A} / \mathrm{g}$ and delivered a capacity of $472 \mathrm{~mA} \cdot \mathrm{h} / \mathrm{g}$ over 100 cycles at $100 \mathrm{~mA} / \mathrm{g}$ as an SIB anode. The combination of $\mathrm{Sb}$ and $\mathrm{Sb}_{2} \mathrm{O}_{3}$ can boost not only the ability of electron diffusion and charge transfer due to the higher conductivity of metal $\mathrm{Sb}$ but also the extra high specific capacity produced by $\mathrm{Sb}_{2} \mathrm{O}_{3}$ in the process of sodiation and desodiation. Moreover, $\mathrm{Na}_{2} \mathrm{O}$ produced during the discharge process combined with graphene can effectively alleviate the volume expansion of electrode materials and improve the cycle stability $[75,83,84]$. In contrast, $\mathrm{Sb}_{2} \mathrm{O}_{3}$ cannot be converted into $\mathrm{Na}_{2} \mathrm{O}$ during the sodium insertion 
Table 1 Summary of the electrochemical performance of metal Sb anodes for SIBs

\begin{tabular}{|c|c|c|c|c|c|c|c|c|}
\hline \multirow[t]{2}{*}{ Samples } & \multicolumn{5}{|l|}{ Cycle stability } & \multicolumn{2}{|l|}{ Rate capability } & \multirow[t]{2}{*}{ Ref } \\
\hline & Potential (V) & $\begin{array}{l}\text { Current } \\
\text { density } \\
(\mathrm{mA} / \mathrm{g})\end{array}$ & $\begin{array}{l}\text { Revers- } \\
\text { ible capacity } \\
(\mathrm{mAh} / \mathrm{g})\end{array}$ & Cycle number & $\begin{array}{l}\text { Capacity } \\
\text { retention } \\
(\%)\end{array}$ & $\begin{array}{l}\text { Current density } \\
\text { (A/g) }\end{array}$ & Capacity (mAh/g) & \\
\hline $20 \mathrm{~nm} \mathrm{Sb}$ & $0.02-1.5$ & 330 & 620 & 200 & 80 & $0.066 / 2.64$ & $609 / 528$ & {$[22]$} \\
\hline $\mathrm{Sb} @ \mathrm{G}_{0.25} \mathrm{~N}_{0.25}$ & $0.01-2$ & 100 & 479 & 100 & 87.4 & $0.5 / 1 / 2$ & $436 / 415 / 351$ & {$[26]$} \\
\hline Self-wrapped $\mathrm{Sb} / \mathrm{C}$ & $0.01-2$ & 200 & 403 & 100 & 92.3 & 32 & 138 & {$[27]$} \\
\hline SblP-S@C foam & $0.05-2.8$ & 100 & 540(100th) & 1000 & 90.7 & $0.4 / 0.8 / 1.6$ & $294 / 267 / 176$ & {$[32]$} \\
\hline $\begin{array}{l}\mathrm{Sb} / \mathrm{ICNNs} \text { (inter- } \\
\text { connected carbon } \\
\text { nanofibers net- } \\
\text { works) }\end{array}$ & $0.01-2$ & 100 & 542.5 & 100 & 92.7 & 3.2 & 325 & {$[35]$} \\
\hline $\begin{array}{l}\text { Pitaya-like Sb@C } \\
\text { microspheres }\end{array}$ & $0.01-2$ & 200 & 628 & 100 & 93 & $0.9 / 1.8 / 3$ & $570 / 412 / 302$ & {$[36]$} \\
\hline $\mathrm{a}-\mathrm{Sb} / \mathrm{NC}$ & $0.01-2.5$ & 1000 & 280.5 & 500 & - & $0.1 / 2$ & $495.5 / 298.7$ & {$[38]$} \\
\hline $\begin{array}{l}\text { Few-layer anti- } \\
\text { monene }\end{array}$ & $0.01-1.5$ & 330 & 620 & 150 & 99.7 & 3.33 & 429 & {$[39]$} \\
\hline $\begin{array}{l}\text { Yolk-shelled Sb@ } \\
\text { Ti-O-P }\end{array}$ & $0.01-3$ & 500 & 760 & 200 & 94 & 10 & 360 & {$[41]$} \\
\hline $\begin{array}{l}\text { Pomegranate Sb@C } \\
\text { yolk-shell }\end{array}$ & $0.01-2.5$ & 200 & & 200 & 99 & $0.05 / 0.5 / 5$ & $637 / 521 / 441$ & {$[42]$} \\
\hline Yolk-shelled Sb@C & $0.01-2$ & 50 & 554 & 200 & 90 & 5 & 315 & {$[43]$} \\
\hline $\begin{array}{l}\text { Nanorod-in-nano- } \\
\text { tube structured } \\
\text { peapod-like } \\
\mathrm{Sb} @ \mathrm{~N}-\mathrm{C}\end{array}$ & $0.01-3.0$ & 2000 & 345.6 & 3000 & - & $0.1 / 10$ & $638.2 / 309.8$ & {$[44]$} \\
\hline $\begin{array}{c}\text { Yolk-shelled Sb@ } \\
\text { NS-3DPCMSs }\end{array}$ & $0.005-3$ & 20,000 & $\sim 331$ & 10,000 & 100 & $5 / 10 / 20$ & $349 / 340 / 334$ & {$[45]$} \\
\hline $\begin{array}{c}\text { Double-Walled Sb@ } \\
\mathrm{TiO}_{2-x} \text { nanotubes }\end{array}$ & $0.01-2.5$ & 2640 & 300 & 1000 & - & $3.3 / 6.6 / 13.2$ & $417 / 388 / 312$ & {$[46]$} \\
\hline Sb nanotubes & $0.01-2.0$ & 1000 & 462.2 & 6000 & 74 & 10 & 286 & {$[47]$} \\
\hline $\begin{array}{l}\text { Hollow Sb@C yolk- } \\
\text { shelled }\end{array}$ & $0.01-2.6$ & 1000 & 208 & 200 & - & $1 / 2$ & $329 / 279$ & {$[48]$} \\
\hline $\begin{array}{c}\mathrm{Sb} @ \mathrm{C} \text { coaxial } \\
\text { nanotubes }\end{array}$ & $0.01-2.0$ & 1000 & 230 & 2000 & - & $5 / 10 / 20$ & $370 / 350 / 310$ & [49] \\
\hline Sb HPs@OCB & $0-3$ & 10,000 & 402 & 300 & 187 & 16 & 345 & {$[52]$} \\
\hline $\mathrm{Sb} @ \mathrm{C} @ \mathrm{TiO}_{2}$ & $0-2$ & 1000 & 193 & 4000 & - & $0.1 / 10$ & $452 / 212$ & {$[53]$} \\
\hline Sb-embedded SiOC & $0.001-2$ & 132 & 510 & 250 & 97 & 13.2 & 453 & {$[54]$} \\
\hline $\mathrm{Sb} @ \mathrm{NC}$ & $0.01-2$ & 100 & 440 & 300 & 74.5 & $2 / 5$ & $285 / 237$ & {$[55]$} \\
\hline $\mathrm{Sb} / \mathrm{NPC}$ composite & $0.01-2$ & 100 & 529.6 & 100 & 97.2 & 1.6 & 357 & {$[56]$} \\
\hline $\mathrm{Sb} / \mathrm{N}-\mathrm{rGO}$ & $0.01-2$ & 100 & 521.7 & 500 & 90.7 & $1 / 2 / 5$ & $403.4 / 360.7 / 304.8$ & {$[57]$} \\
\hline $\begin{array}{l}\text { Sb nanorod@ }(\mathrm{N}, \\
\text { S-C) (cross-linked) } \\
\text { Sb CCTHNs }\end{array}$ & $\begin{array}{l}0.01-2.5 \\
0.01-2.5\end{array}$ & $\begin{array}{l}1000 \\
2000\end{array}$ & $\begin{array}{l}398 \\
345.4\end{array}$ & $\begin{array}{l}150 \\
1600\end{array}$ & $\overline{-}$ & $\begin{array}{l}2 / 5 / 10 \\
0.1 / 5\end{array}$ & $\begin{array}{l}534.4 / 430.8 / 374.7 \\
558 / 347.1\end{array}$ & $\begin{array}{l}{[58]} \\
{[59]}\end{array}$ \\
\hline $\begin{array}{l}\text { Sb@3D Cu NWAs } \\
\text { (nanowire arrays) }\end{array}$ & $0.01-1.5$ & 330 & 605.3 & 200 & 92.7 & 3.3 & 554.6 & {$[60]$} \\
\hline $\begin{array}{l}\text { Self-supported Sb } \\
\text { prisms }\end{array}$ & $0-2$ & 330 & 578 & 100 & 91.9 & 3.3 & 409 & {$[61]$} \\
\hline $\begin{array}{l}\text { Porous } \mathrm{Sb} / \mathrm{C} \text { com- } \\
\text { posite }\end{array}$ & $0.01-2.5$ & 100 & 423 & 200 & 90.3 & 15 & 226 & {$[62]$} \\
\hline $\begin{array}{l}\text { Sb/PAA/Pullulan- } \\
\text { CN }\end{array}$ & $0.01-2$ & 660 & 400 & 200 & 76 & 13.2 & 320 & {$[63]$} \\
\hline $\begin{array}{l}\text { Electrospun } \\
\text { SbNP@C fibers }\end{array}$ & $0-2$ & 2000 & 185 & 300 & 75 & $4 / 5 / 6$ & $123 / 104 / 88$ & {$[64]$} \\
\hline $\mathrm{Sb} @ \mathrm{C}$ & $0.01-2.0$ & 180 & 494 & 300 & 92.3 & $1.2 / 3 / 4.2$ & $320 / 267 / 228$ & {$[65]$} \\
\hline
\end{tabular}


Table 1 (continued)

\begin{tabular}{|c|c|c|c|c|c|c|c|c|}
\hline \multirow[t]{2}{*}{ Samples } & \multicolumn{5}{|l|}{ Cycle stability } & \multicolumn{2}{|l|}{ Rate capability } & \multirow[t]{2}{*}{ Ref } \\
\hline & Potential (V) & $\begin{array}{l}\text { Current } \\
\text { density } \\
(\mathrm{mA} / \mathrm{g})\end{array}$ & $\begin{array}{l}\text { Revers- } \\
\text { ible capacity } \\
(\mathrm{mAh} / \mathrm{g})\end{array}$ & Cycle number & $\begin{array}{l}\text { Capacity } \\
\text { retention } \\
(\%)\end{array}$ & $\begin{array}{l}\text { Current density } \\
(\mathrm{A} / \mathrm{g})\end{array}$ & Capacity $(\mathrm{mAh} / \mathrm{g})$ & \\
\hline $\begin{array}{l}\text { Spherical nano- } \\
\text { Sb@C }\end{array}$ & $0.01-2$ & 100 & 435 & 500 & 88.5 & $355 / 324 / 270$ & $1 / 2 / 4$ & [66] \\
\hline Spherical Sb/C & $0.01-2$ & 100 & 641 & 150 & 78.3 & $0.4 / 0.6 / 1.2$ & $498 / 416 / 340$ & [67] \\
\hline $\mathrm{Sb} / \mathrm{rGO}$ paper & $0.01-2.0$ & 1000 & 467 & 100 & - & 20 & 237 & [68] \\
\hline $\mathrm{Sb}-\mathrm{O}-\mathrm{C} / \mathrm{C}$ & $0.1-2$ & 500 & 454 & 700 & 89 & 3.2 & 351 & [69] \\
\hline $\begin{array}{l}\text { Sandwich-like G@ } \\
\text { Sb@C }\end{array}$ & $0.01-2$ & 100 & 569.5 & 200 & - & 5 & 433 & [70] \\
\hline FernF leaf-like Sb & $0.01-2$ & 500 & 598 & 150 & 98.5 & $3 / 5 / 10$ & $505 / 500 / 498$ & [71] \\
\hline $\mathrm{Sb} @ \mathrm{PCFs}$ & $0.01-3$ & 200 & 560 & 80 & 96 & 1.5 & 385 & [72] \\
\hline Porous Sb-C & $0-1.5$ & 660 & 522 & 195 & 82.4 & 6.6 & 357 & [73] \\
\hline $\mathrm{Sb}-\mathrm{N} / \mathrm{C}$ & $0.01-3$ & 2000 & 220 & 180 & - & $0.05 / 10$ & $325 / 142$ & [74] \\
\hline
\end{tabular}

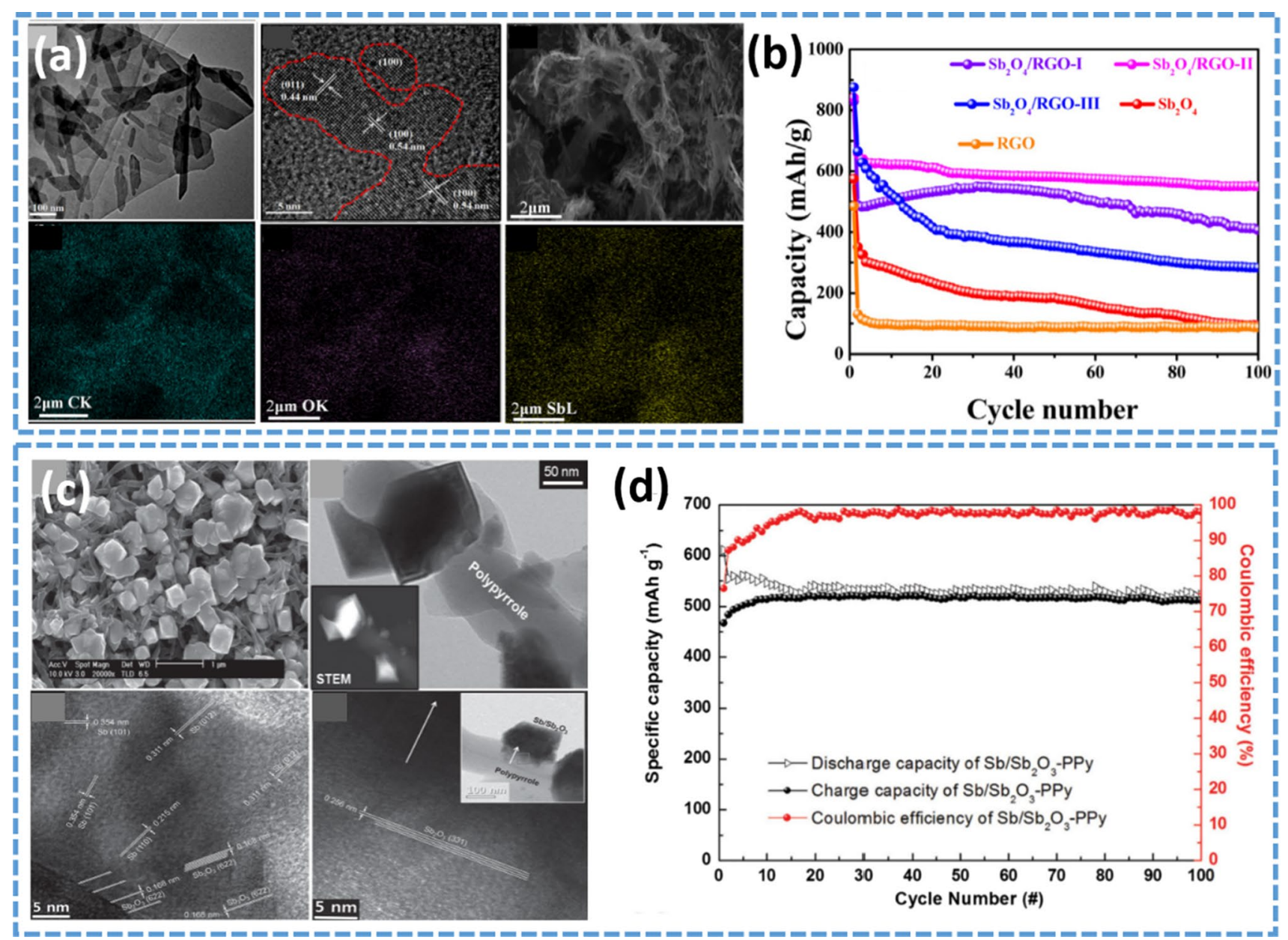

Fig. 7 a TEM images and EDS mapping of $\mathrm{Sb}_{2} \mathrm{O}_{4}$ nanorods anchored on reduced graphene oxide $\left(\mathrm{Sb}_{2} \mathrm{O}_{4} / \mathrm{RGO}\right)$, $\mathbf{b}$ cycling performance of $\mathrm{Sb}$ nanorods composite at $50 \mathrm{~mA} / \mathrm{g}$. Reproduced with permission from Ref. [81]. Copyright 2017, Elsevier. c SEM and TEM images of $3 \mathrm{D}$ porous $\mathrm{Sb} / \mathrm{Sb}_{2} \mathrm{O}_{3}$ anode materials, $\mathbf{d}$ the corresponding cycling performance of $3 \mathrm{D}$ porous $\mathrm{Sb} / \mathrm{Sb}_{2} \mathrm{O}_{3}$ electrode material at a current density of $66 \mathrm{~mA} / \mathrm{g}$. Reproduced with permission from Ref. [85]. Copyright 2015, John Wiley \& Sons, Inc 
process, and $\mathrm{Sb}_{2} \mathrm{O}_{3}$ itself plays the role of reducing internal stress [85]. As shown in Fig. 7c, Nam and co-workers synthesized 3D porous $\mathrm{Sb} / \mathrm{Sb}_{2} \mathrm{O}_{3}$ anode materials via a simple electrodeposition project that exhibited a reduced charge capacity by $43.3 \%$ from $66 \mathrm{~mA} / \mathrm{g}$ to $3.3 \mathrm{~A} / \mathrm{g}$ and maintained $512.01 \mathrm{~mA} \cdot \mathrm{h} / \mathrm{g}$ after 100 cycles as an anode in SIBs (Fig. 7d). The study found that the $\mathrm{Sb}_{2} \mathrm{O}_{3}$ framework can act as a buffer matrix for metal $\mathrm{Sb}$ and regulate the internal stress produced by $\mathrm{Sb}$ during the charge and discharge processes, thus improving the cyclic stability of electrode materials. In addition, flexible SIB anode materials have also received attention because of the increasing demand for wearable and foldable devices. For instance, Fei et al. [86] constructed a flexible $\mathrm{Sb}_{2} \mathrm{O}_{3}$ /carbon cloth composite via a simple solvothermal strategy; the carbon cloth has good conductivity, and there is a strong chemical bond between the carbon cloth and the $\mathrm{Sb}_{2} \mathrm{O}_{3}$ in this composite hybrid. Unexpectedly, the flexible composite material exhibited a high discharge specific capacity of $1248 \mathrm{~mA} \cdot \mathrm{h} / \mathrm{g}$ in the first cycle and sustained a high capacity of $900 \mathrm{~mA} \cdot \mathrm{h} / \mathrm{g}$ over the 100 cycles. Although the composite of antimony oxide and different conductive materials have been studied, a method to produce a composite with various conductive materials in the future and give full play to the advantages of conductive materials remains a problem.

Table 2 exhibits the electrochemical properties of the reported $\mathrm{Sb}$ oxides as the anode in SIBs. It is not difficult to find that $\mathrm{Sb}$ oxides combined with a variety of conductive matrices can exhibit more robust stability and excellent rate in Na storage; however, this configuration often sacrifices its high specific capacity advantage [87-90]. Therefore, a heterojunction interface should be employed to compensate for the loss of theoretical capacity, or a combination with other active materials of high theoretical capacity and excellent conductivity to enhance the Na storage capability of Sb-based oxides should be used.

\section{Antimony Sulfides/Selenides for Sodium-Ion Batteries (SIBs)}

Theoretically, antimony sulfides and antimony selenides have similar electrochemical reaction mechanisms in the process of sodiation/desodiation, i.e., conversion reaction and alloying reaction during the full charging and discharging processes. Both antimony sulfides and antimony selenides display high theoretical capacity when they are used as an anode in SIBs. The most studied $\mathrm{Sb}_{2} \mathrm{~S}_{3}$ as a representative reaction process could be expounded by the following formulas [91-93]:

$\mathrm{Sb}_{2} \mathrm{~S}_{3}+6 \mathrm{Na}^{+}+6 \mathrm{e}^{-} \leftrightarrow 2 \mathrm{Sb}+3 \mathrm{Na}_{2} \mathrm{~S}\left(\mathrm{Sb}_{2} \mathrm{~S}_{3}:\right.$ conversion reaction $)$

$2 \mathrm{Sb}+6 \mathrm{Na}^{+}+6 \mathrm{e}^{-} \leftrightarrow 2 \mathrm{Na}_{3} \mathrm{Sb}\left(\mathrm{Sb}_{2} \mathrm{~S}_{3}:\right.$ alloying reaction $)$

In the above reaction, $1 \mathrm{~mol}$ of $\mathrm{Sb}_{2} \mathrm{~S}_{3}$ can cause $12 \mathrm{~mol}$ of sodium ions and electrons to participate in the reaction together, resulting in a theoretical capacity of $946 \mathrm{~mA} \bullet \mathrm{h} / \mathrm{g}$

Table 2 Summary of the electrochemical performance of Sb-based oxide anodes for SIBs

\begin{tabular}{|c|c|c|c|c|c|c|c|c|}
\hline \multirow[t]{2}{*}{ Samples } & \multicolumn{5}{|l|}{ Cycle stability } & \multicolumn{2}{|l|}{ Rate capability } & \multirow[t]{2}{*}{ Ref } \\
\hline & Potential (V) & $\begin{array}{l}\text { Current } \\
\text { density } \\
(\mathrm{mA} / \mathrm{g})\end{array}$ & $\begin{array}{l}\text { Revers- } \\
\text { ible capacity } \\
(\mathrm{mAh} / \mathrm{g})\end{array}$ & Cycle number & $\begin{array}{l}\text { Capacity } \\
\text { retention } \\
(\%)\end{array}$ & Current density (A/g) & Capacity (mAh/g) & \\
\hline $\mathrm{Sb}_{2} \mathrm{O}_{3} / \mathrm{Sb} @$ graphene & $0.01-2$ & 100 & 525.4 & 275 & 92.7 & 5 & 220.8 & [75] \\
\hline $\mathrm{SbO}_{x} / \mathrm{RGO}$ & $0-2$ & 1000 & 605.3 & 100 & 95 & 5 & 352 & [76] \\
\hline $\mathrm{SbO}_{x} @ \mathrm{CF}$ & $0.01-2.0$ & 100 & 451 & 100 & 98 & 4 & 114 & [77] \\
\hline Tube-like $\mathrm{Sb}_{2} \mathrm{O}_{4}$ & $0.01-2.5$ & 100 & 381.9 & 100 & - & - & - & [78] \\
\hline $\mathrm{Sb}_{2} \mathrm{O}_{3} / \mathrm{CNTs} / \mathrm{rGO}$ & $0.001-3.0$ & 200 & 456.5 & 50 & 100 & 3 & 345.4 & [79] \\
\hline $\mathrm{Sb}_{2} \mathrm{O}_{3} / \mathrm{RGO}$ & $0-2.0$ & 100 & 509 & 50 & 98.8 & $0.5 / 1$ & $435.2 / 385.98$ & [80] \\
\hline $\mathrm{Sb}_{2} \mathrm{O}_{4} / \mathrm{RGO}$ & $0.01-3$ & 20 & 659 & 100 & 83.6 & 1 & 401 & [81] \\
\hline $\mathrm{Sb}_{2} \mathrm{O}_{3} / \mathrm{Ti}_{3} \mathrm{C}_{2} \mathrm{~T} x$ & $0.01-2.5$ & 100 & 430.5 & 100 & 100 & 2 & 295 & [82] \\
\hline $\mathrm{Sb} / \mathrm{Sb}_{2} \mathrm{O}_{3}$ & $0.005-3$ & 66 & 670 & 100 & 91.8 & 3.3 & 212 & [83] \\
\hline Porous $\mathrm{Sb} / \mathrm{Sb}_{2} \mathrm{O}_{3}$ & $0.02-1.5$ & 660 & 582 & 180 & 92.8 & 10 & 412 & [84] \\
\hline $\mathrm{Sb} / \mathrm{Sb}_{2} \mathrm{O}_{3}-\mathrm{PPy}$ & $0.001-1.5$ & 66 & 520.6 & 100 & 98.34 & 3.3 & 299.46 & [85] \\
\hline $\mathrm{Sb}_{2} \mathrm{O}_{3} /$ carbon cloth & $0.01-3.0$ & 50 & 1250 & 100 & 72 & $0.1 / 0.2 / 0.5$ & $675 / 540 / 340$ & [86] \\
\hline $\mathrm{Sb}_{2} \mathrm{O}_{3}$ & $0.01-2$ & 500 & 414 & 200 & - & $0.05 / 5$ & $550 / 265$ & [87] \\
\hline 3D Ni@NiSb/Sb $\mathrm{Sb}_{3}$ & $0.01-2.5$ & 200 & 445 & 200 & 89 & $0.8 / 1.6 / 3.2$ & $413 / 368 / 326$ & [88] \\
\hline $\mathrm{Sb}_{2} \mathrm{O}_{4}$ thin film & $0.01-3.5$ & $1 / 70 \mathrm{C}$ & 896 & 20 & 80.8 & - & - & [89] \\
\hline $\mathrm{Sb}_{2} \mathrm{O}_{3}$ micro-bundles & $0.01-2.5$ & 500 & 418.3 & 140 & - & $0.05 / 2$ & $538.4 / 387$ & [90] \\
\hline
\end{tabular}


via this process as an anode in SIBs $[7,17,18,20]$. Similarly, the widely reported $\mathrm{Sb}_{2} \mathrm{Se}_{3}$ also experienced a two-step reaction; the conversion and alloying processes are described in the following equations [94]:

$$
\begin{aligned}
& \mathrm{Sb}_{2} \mathrm{Se}_{3}+6 \mathrm{Na}^{+}+6 \mathrm{e}^{-} \leftrightarrow 2 \mathrm{Sb} \\
& +3 \mathrm{Na}_{2} \mathrm{Se}\left(\mathrm{Sb}_{2} \mathrm{Se}_{3}: \text { conversion reaction }\right)
\end{aligned}
$$

$\mathrm{Sb}+3 \mathrm{Na}^{+}+3 \mathrm{e}^{-} \leftrightarrow \mathrm{Na}_{3} \mathrm{Sb}\left(\mathrm{Sb}_{2} \mathrm{Se}_{3}\right.$ : alloying reaction $)$

The theoretical capacity of sodium storage contributed by the resulting material of the above two-step reaction is $670 \mathrm{~mA} \cdot \mathrm{h} / \mathrm{g}\left(1 \mathrm{~mol} \mathrm{Sb}_{2} \mathrm{Se}_{3}-9 \mathrm{~mol} \mathrm{Na}^{+}\right)[7,17,18,20]$. Evidently, the theoretical capacity of antimony selenides is less than that of antimony sulfides and oxides and it is equivalent to that of metal $\mathrm{Sb}$.

Antimony sulfides and selenides suffer from several issues when used in sodium storage. For instance, the weak conductivity of antimony sulfides and selenides, unavoidable volume expansion, and even the discharge products $\left(\mathrm{Na}_{2} \mathrm{~S}\right.$ and $\mathrm{Na}_{2} \mathrm{Se}$ ) can cause the shuttle effect; a similar process occurs in lithium-sulfur batteries [95-99]. In view of these negative phenomena, many strategies have been adopted to alleviate them. Among these strategies, designing a hollow structure is widely used; a similar strategy is used to address issues in the use of the metal Sb. As presented in Fig. 8a, Ge et al. [100] prepared a single-shelled hollow-sphere $\mathrm{Sb}_{2} \mathrm{~S}_{3}$ coated with carbon via an Oswald ripening process. The single-shelled hollow structure of large void space delivered a capacity of around 700 and $180 \mathrm{~mA} \cdot \mathrm{h} / \mathrm{g}$ at 0.2 and $6.4 \mathrm{~A} / \mathrm{g}$, respectively. Hollow-sphere $\mathrm{Sb}_{2} \mathrm{~S}_{3}$ maintained $550.8 \mathrm{~mA} \cdot \mathrm{h} / \mathrm{g}$ over 70 cycles. This performance of the hollow-sphere $\mathrm{Sb}_{2} \mathrm{~S}_{3}$ is better than that of the unmodified $\mathrm{Sb}_{2} \mathrm{~S}_{3}$, thus confirming the structural advantages of the single-shelled hollow structure. Inspired by the single-shelled hollow structure, multi-shelled hollow SIB anode materials have been prepared and applied as the anode in SIBs [101-103]. For instance, Xie and co-workers [104] reported hollow multishelled $\mathrm{Sb}_{2} \mathrm{~S}_{3}$ (Fig. 8b) formed by synthesizing a zeolitic

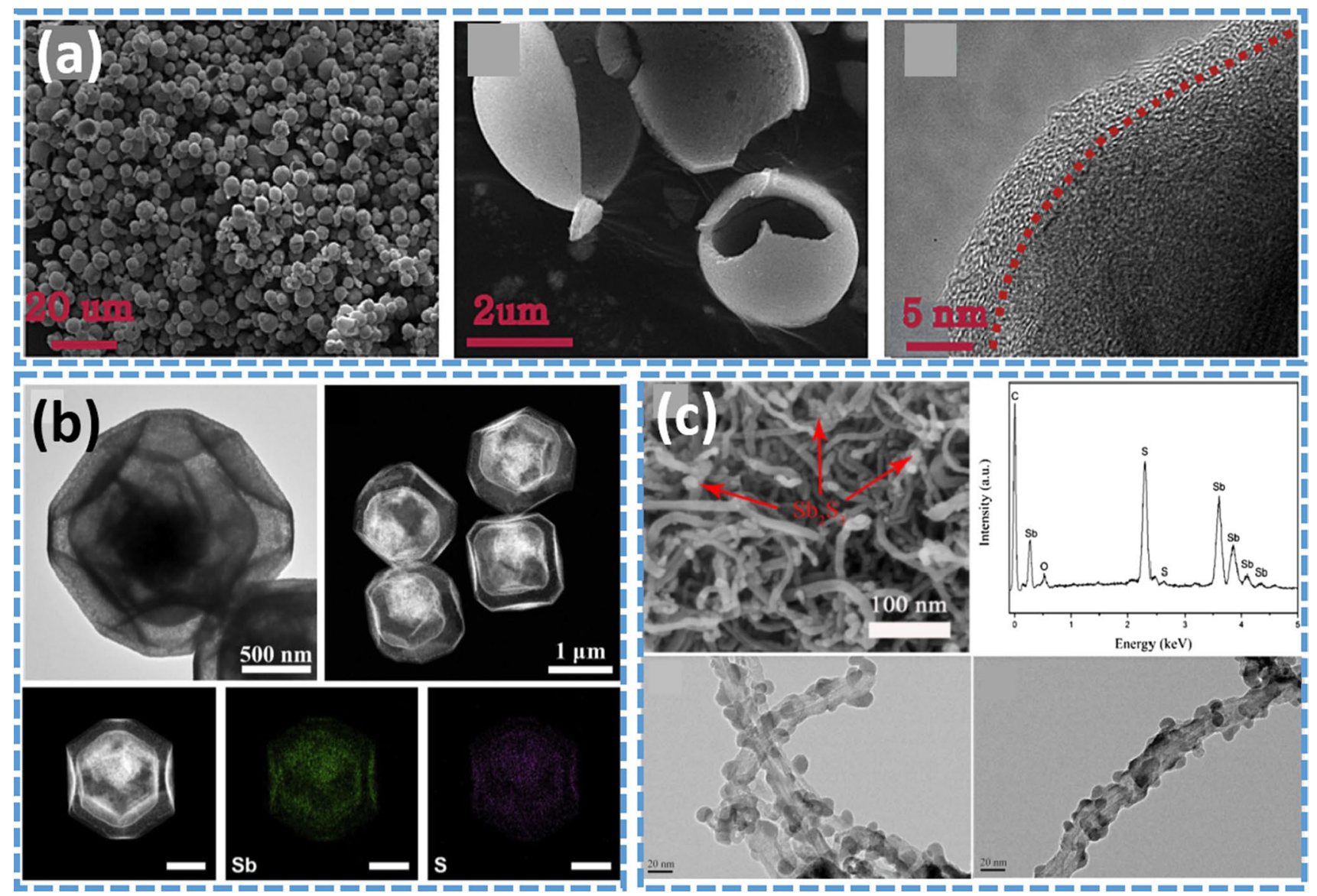

Fig. 8 a SEM and TEM images and EDS of single-shelled hollowsphere $\mathrm{Sb}_{2} \mathrm{~S}_{3}$ coated with carbon. Reproduced with permission from Ref. [100]. Copyright 2018, Elsevier. b TEM images and EDS mapping of hollow multi-shelled $\mathrm{Sb}_{2} \mathrm{~S}_{3}$ anode materials. Reproduced with permission from Ref. [104]. Copyright 2019, Elsevier. c SEM and TEM images of $\mathrm{Sb}_{2} \mathrm{~S}_{3}$ multi-walled carbon nanotubes composites. Reproduced with permission from Ref. [105]. Copyright 2017, Elsevier 
imidazolate framework 8 (ZIF-8) and exchanging the $\mathrm{Sb}^{3+}$ and $\mathrm{Zn}^{2+}$. This structure has the characteristics of high stability for sodium storage by virtue of the hollow structure and high gravimetric energy density. The hollow multi-level structure material exhibited a reversible capacity of 308 and $116 \mathrm{~mA} \bullet \mathrm{h} / \mathrm{g}$ at 0.1 and $2 \mathrm{~A} / \mathrm{g}$, respectively. Furthermore, compared with pristine $\mathrm{Sb}_{2} \mathrm{~S}_{3}$, this multiple-shelled structure showed more stable cycle and higher specific capacity. In addition, similar to the improvement strategy for metal $\mathrm{Sb}$, the one-dimensional hollow tube embedded $\mathrm{Sb}_{2} \mathrm{~S}_{3}$ can also deliver excellent performance in sodium storage because of the one-dimensional high-speed transmission channel and hollow structure that can effectively accelerate charge transfer and relieve internal stress during charging/discharging. Figure $8 \mathrm{c}$ shows $\mathrm{Sb}_{2} \mathrm{~S}_{3}$ multi-walled carbon nanotube composites constructed via precipitation and subsequent thermal treatment [105]. This composite material has a hollow framework with a large specific surface area and large expansion space that can accelerate the charge transfer and effectively buffer the volume expansion when used as an anode for SIBs. The results of charge/discharge of $\mathrm{Na}^{+}$storage showed a capacity of 442.1 and $339.1 \mathrm{~mA} \cdot \mathrm{h} / \mathrm{g}$ at 50 and $1000 \mathrm{~mA} / \mathrm{g}$, respectively. Clearly, the hollow structure can transfer higher capacity and maintain a stable structure in the repeated sodium insertion and escape process. Nonetheless, the long-term cycle stability of the composite structure with antimony sulfide/selenide requires further improvement.

Another exciting strategy involves the combination of doping and modifying the carbon materials with antimony sulfides and antimony selenides. For example, Liu's group [106] reported the production of sulfur-doped graphene sheets combined with nanostructured $\mathrm{Sb}_{2} \mathrm{~S}_{3}$ (Fig. 9a). The doped sulfur in graphene can enhance the electronic coupling between $\mathrm{Sb}_{2} \mathrm{~S}_{3}$ and graphene by forming strong chemical bonds. With the aid of this chemical bonding, the composite material achieved a high capacity of 792.8 and $591.6 \mathrm{~mA} \cdot \mathrm{h} / \mathrm{g}$ at 0.05 and $5 \mathrm{~A} / \mathrm{g}$, respectively. Moreover, the sample maintained an $83 \%$ capacity retention rate after 900 cycles at $2 \mathrm{~A} / \mathrm{g}$. As shown in Fig. 9b, Xie and co-workers [107] fabricated silicon-oxygen-carbon nanofibers embedded with $\mathrm{Sb}_{2} \mathrm{~S}_{3}$ via electrospinning and hydrothermal reaction. The Si-O-C nanofibers accelerate electron and ion transport and alleviate the volume expansion of active substances. Thus, the nanofibers offered a high capacity of $532 \mathrm{~mA} \cdot \mathrm{h} / \mathrm{g}$ at $0.1 \mathrm{~A} / \mathrm{g}$ and exhibited a specific capacity of $221 \mathrm{~mA} \bullet \mathrm{h} / \mathrm{g}$ at $5 \mathrm{~A} / \mathrm{g}$ for sodium storage. Furthermore, the sample displayed a reversible discharge capacity of $321 \mathrm{~mA} \bullet \mathrm{h} / \mathrm{g}$ after 200 cycles. As shown in Fig. 9c, Choi et al. [95] designed an amorphous phosphorus/carbon framework embedded with $\mathrm{Sb}_{2} \mathrm{~S}_{3}$ via a mechanochemical method followed by heat treatment. Doping phosphorus in amorphous carbon can enhance the conductivity of the matrix and prevent the aggregation of active substances in sodium storage. As a result, the sample achieved a reversible capacity of 654 and $390 \mathrm{~mA} \bullet \mathrm{h} / \mathrm{g}$ at 0.05 and $2 \mathrm{~A} / \mathrm{g}$, respectively (Fig. 9d), as well as exhibited a capacity retention rate of $93.4 \%$ over 100 cycles at $50 \mathrm{~mA} / \mathrm{g}$. Similar to the modification strategy of metal Sb, the silicon-oxygen-carbon $(\mathrm{Si}-\mathrm{O}-\mathrm{C})$ structure can also replace the traditional pure carbon materials (e.g., graphene, amorphous carbon, and doped carbon) as the reinforcement matrix to combine with $\mathrm{Sb}_{2} \mathrm{~S}_{3}$, thereby improving the cyclicality and conductivity while inhibiting the volume expansion during the charging/discharging [54]. The use of diverse designs of carbon materials can improve the electrochemical performance of antimony sulfides/selenides. Thus, further modification of the carbon architecture represents a practical pathway for improvements by significantly enhancing ion and electron transport, increasing the capacity of sodium storage, and even inhibiting the aggregation of active substances.

Note that the need for traditional powder electrode materials to be prepared as a slurry in advance makes the process tedious and reduces the tapped density of the cell using a traditional electrode. Moreover, the introduction of binders is detrimental to the Coulombic efficiency during battery operation [108-110]. To address these issues, the anode materials of self-supporting for SIBs emerged. Self-supporting electrode materials of antimony sulfides and antimony selenides can avoid the use of additional conductive carbon and binder while exhibiting a high capacity of sodium storage as good as that of powder electrode materials. As a typical example, Lu and co-workers [19], using a facile hydrothermal assembly strategy, demonstrated a self-supported three-dimensional porous graphene foam with $\mathrm{Sb}_{2} \mathrm{~S}_{5}$ nanoparticles $(\sim 5 \mathrm{~nm})$ encapsulated in the framework, as displayed in Fig. 10a. The as-prepared composite can be used as an electrode without employing a binder, a conductive agent, and a current collector. Moreover, the stable combination of ultra-small nanoparticles with 3D porous graphene promotes $\mathrm{Na}^{+}$transfer and electron diffusion. This self-supported electrode delivered the ultrahigh rate capacity of 845 and $525 \mathrm{~mA} \cdot \mathrm{h} / \mathrm{g}$ at 0.1 and $10 \mathrm{~A} / \mathrm{g}$, respectively (Fig. 10b), and sustained $91.6 \%$ capacity retention over 300 cycles at $200 \mathrm{~mA} / \mathrm{g}$. Similarly, for antimony selenides, Luo et al. [111] synthesized a free-standing membrane with $\mathrm{Sb}_{2} \mathrm{Se}_{3}$ nanowires through a facile hydrothermal synthesis and vacuum filtration (Fig. 10c). This free-standing composite of satisfactory flexibility and integrity achieved a reversible capacity of $360 \mathrm{~mA} \bullet \mathrm{h} / \mathrm{g}$ at $0.1 \mathrm{~A} / \mathrm{g}$ and maintained $289 \mathrm{~mA} \bullet \mathrm{h} / \mathrm{g}$ after 50 cycles (Fig. 10d). Although antimony sulfides and antimony selenides have high specific capacities, their poor cycle stability still needs to be improved. In addition, self-supporting flexible antimony sulfur/selenide should also be developed to realize wearable and foldable electronic devices. 


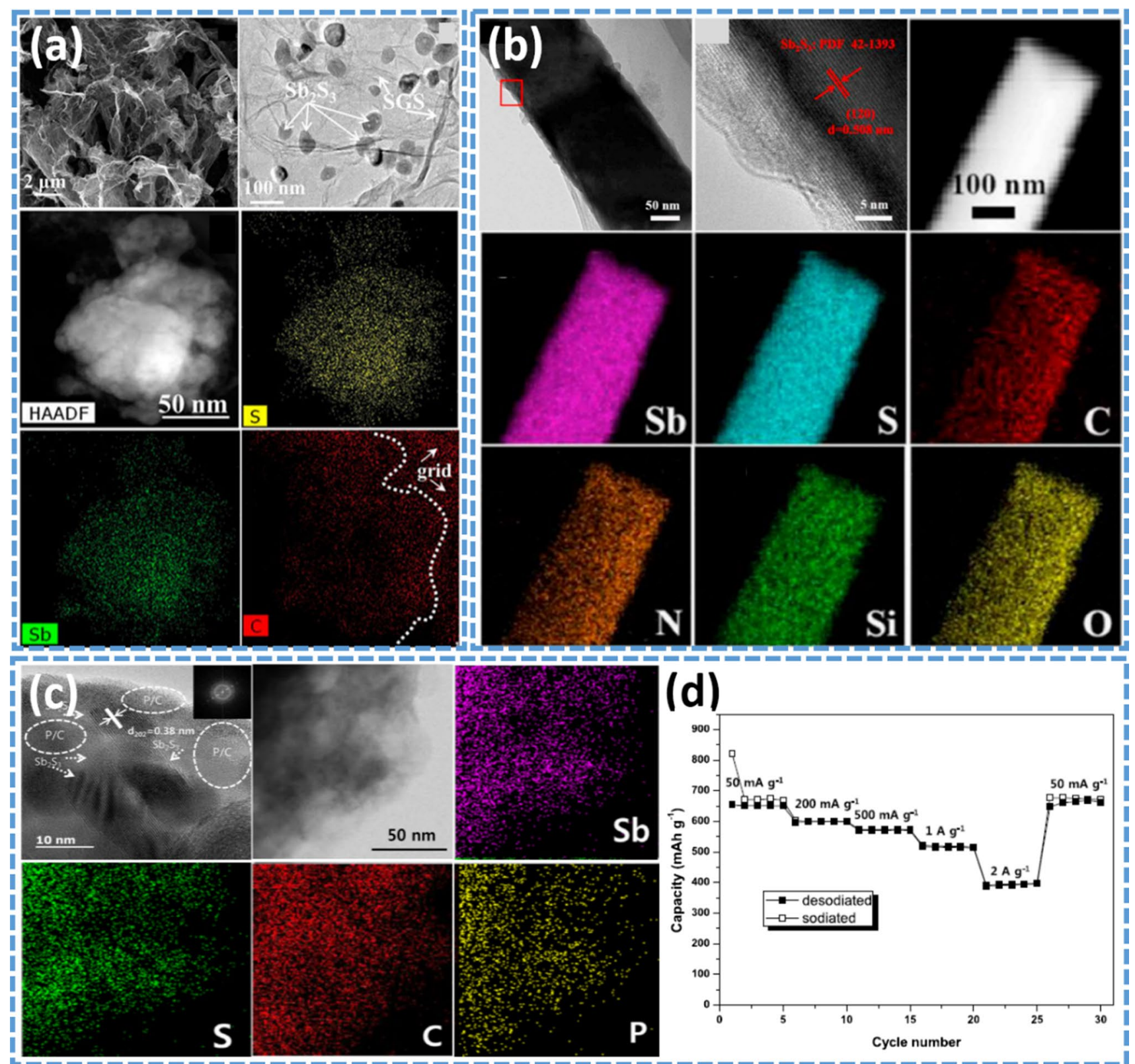

Fig. 9 a SEM and TEM images and EDS mapping of nanostructured $\mathrm{Sb}_{2} \mathrm{~S}_{3}$ combined with S-doped graphene sheets. Reproduced with permission from Ref. [106]. Copyright 2016, American Chemical Society. b TEM images and EDS mapping of silicon-oxygen-carbon $(\mathrm{Si}-\mathrm{O}-\mathrm{C})$ nanofibers embedded $\mathrm{Sb}_{2} \mathrm{~S}_{3}$. Reproduced with permission from Ref. [107]. Copyright 2019, Elsevier. c TEM images and

Table 3 presents the reported $\mathrm{Sb}$-based sulfides and selenides as anode materials for SIBs and their corresponding electrochemical performance. Although most Sb-based sulfides and selenides electrode materials exhibit high specific capacity in sodium storage, their cycle stability is not ideal [112-116]. In this regard, more attention should be focused on improving their cycle stability during charge and discharge processes.
EDS mapping of amorphous phosphorus/carbon framework embedded $\mathrm{Sb}_{2} \mathrm{~S}_{3}$, $\mathbf{d}$ rate capability of amorphous phosphorus/carbon framework embedded $\mathrm{Sb}_{2} \mathrm{~S}_{3}$ at various current densities from 0.05 to $2 \mathrm{~A} / \mathrm{g}$. Reproduced with permission from Ref. [95]. Copyright 2016, Elsevier

\section{Antimony-Based Alloy for Sodium-Ion Batteries}

In recent years, $\mathrm{Sb}$-based alloys have developed rapidly. The advantage of Sb-based alloys is that the introduction of suitable phases can change the electrochemical properties of $\mathrm{Sb}$ and alleviate its volume expansion during the process of sodium storage. In addition, the phase with sodium storage characteristics better cooperates with Sb [117-120]. 


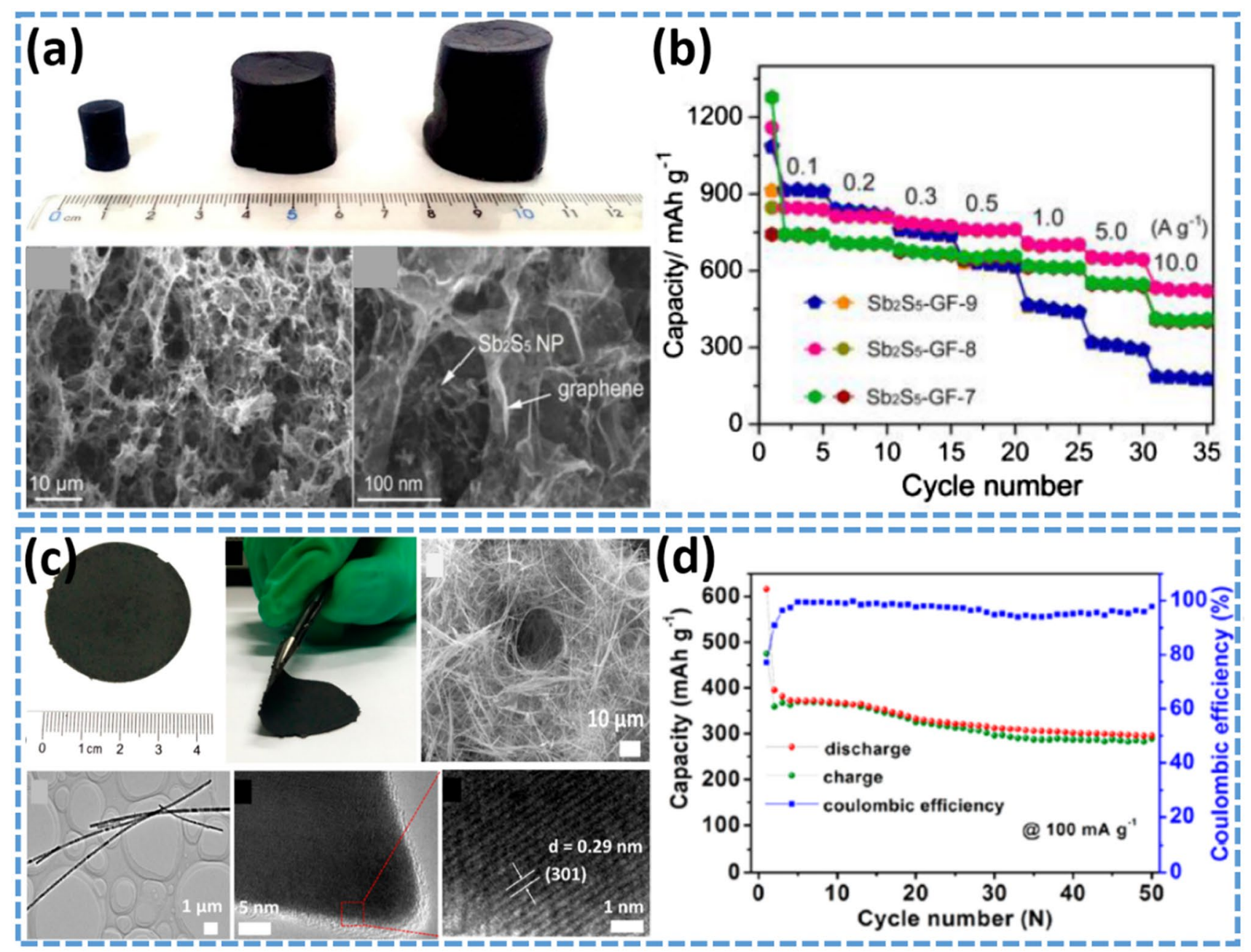

Fig. 10 a Photographs of $\mathrm{Sb}_{2} \mathrm{~S}_{5}$-GO dispersion, after hydrothermal reduction, and the corresponding slices, b SEM images and EDS mapping 3D porous $\mathrm{Sb}_{2} \mathrm{~S}_{5}$-GF-8 composite, rate capability of 3D porous $\mathrm{Sb}_{2} \mathrm{~S}_{5}$-GF-8 composite at various current densities from 0.1 to $10 \mathrm{~A} / \mathrm{g}$. Reproduced with permission from Ref. [19]. Copyright 2017, American Chemical Society. c The front view and side view

Generally, many types of binary Sb-based intermetallic compounds, and even ternary Sb-based alloys, can be synthesized based on the alloy phase diagram. For instance, Farbod and co-workers [121] firstly reported ternary SnGe-Sb thin-film alloys with the particle size of $10-15 \mathrm{~nm}$ for SIB anodes. A half battery test of Sn-Ge-Sb showed a rate capacity of 833 and $381 \mathrm{~mA} \cdot \mathrm{h} / \mathrm{g}$ at 85 and $8500 \mathrm{~mA} / \mathrm{g}$, respectively. The cyclic test maintained a specific capacity of $662 \mathrm{~mA} \cdot \mathrm{h} / \mathrm{g}$ after 50 cycles at $85 \mathrm{~mA} / \mathrm{g}$. Such high capacity comes from the interaction between the ternary alloy phases. However, the poor conductivity and the inevitable volume expansion of Sb-based alloys reduce the cycle period during the sodium storage process. Therefore, similar methods for improving the above-mentioned Sb-based materials are also widely utilized in Sb-based alloys. photographs, SEM and TEM images of the $\mathrm{Sb}_{2} \mathrm{Se}_{3}$ ultra-long nanowire-based membrane, $\mathbf{d}$ the corresponding cycle performance and Coulombic efficiency of $\mathrm{Sb}_{2} \mathrm{Se}_{3}$ ultra-long nanowire-based membrane at a current density of $100 \mathrm{~mA} / \mathrm{g}$. Reproduced with permission from Ref. [111]. Copyright 2016, American Chemical Society

For example, Liu et al. [122] reported the production of 3D NiSb intermetallic hollow nanospheres via a smart lowtemperature crystallization and galvanic replacement reaction (Fig. 11a). This 3D interconnected hollow nanosphere structure possesses many pores that can accommodate the huge volume change and reduce the stress that arises from sodium storage. When used as an anode in SIBs, the NiSb electrode demonstrated a capacity of $201 \mathrm{~mA} \cdot \mathrm{h} / \mathrm{g}$ at $15 \mathrm{C}$ (Fig. 11b) and showed a discharge capacity of 400, 372, and $230 \mathrm{~mA} \cdot \mathrm{h} / \mathrm{g}$ at 1,5 , and $10 \mathrm{C}$ over 150 cycles, respectively. Moreover, graphene and RGO are widely used as additives to modify materials because of their excellent conductivity and mechanical strength. As shown in Fig. 11c, Ji and co-workers [123] prepared a composite of SnSb alloy nanoparticles (20-30 nm) and RGO via hydrothermal reaction and thermal reduction. The 
Table 3 Summary of the electrochemical performance of Sb-based sulfide anodes for SIBs

\begin{tabular}{|c|c|c|c|c|c|c|c|c|}
\hline \multirow[t]{2}{*}{ Samples } & \multicolumn{5}{|l|}{ Cycle stability } & \multicolumn{2}{|c|}{ Rate capability } & \multirow[t]{2}{*}{ Ref } \\
\hline & Potential (V) & $\begin{array}{l}\text { Current } \\
\text { density } \\
(\mathrm{mA} / \mathrm{g})\end{array}$ & $\begin{array}{l}\text { Revers- } \\
\text { ible capacity } \\
(\mathrm{mAh} / \mathrm{g})\end{array}$ & Cycle number & $\begin{array}{l}\text { Capacity } \\
\text { retention } \\
(\%)\end{array}$ & $\begin{array}{l}\text { Current } \\
\text { density } \\
(\mathrm{A} / \mathrm{g})\end{array}$ & Capacity $(\mathrm{mAh} / \mathrm{g})$ & \\
\hline $3 \mathrm{D} \mathrm{Sb}_{2} \mathrm{~S}_{5}-\mathrm{GF}$ & $0.1-3$ & 200 & 816.6 & 300 & 91.6 & 10 & 525 & [19] \\
\hline $\mathrm{rGO} / \mathrm{Sb}_{2} \mathrm{~S}_{3}$ & $0.01-2.5$ & 50 & 670 & 50 & 95 & 3 & 520 & [91] \\
\hline $\begin{array}{l}\text { Carbon-coated } \mathrm{Sb}_{2} \mathrm{~S}_{3} \\
\text { nanorods }\end{array}$ & $0-2$ & 100 & 570 & 100 & - & $1 / 2$ & $415 / 337$ & {$[92]$} \\
\hline $\mathrm{Sb}_{2} \mathrm{~S}_{3}$-graphite & $0.01-2.5$ & 1000 & 662 & 100 & 99.1 & $5 / 7 / 10$ & $609 / 583 / 536$ & [93] \\
\hline $\mathrm{Sb}_{2} \mathrm{~S}_{3}$ in $\mathrm{P} / \mathrm{C}$ & $0.005-2$ & 100 & 654 & 100 & 93.4 & 2 & 390 & [95] \\
\hline Amorphous $\mathrm{Sb}_{2} \mathrm{~S}_{3}$ & $0.01-2.5$ & 50 & 586 & 100 & 87.4 & 3 & 534 & [96] \\
\hline $1 \mathrm{D} \mathrm{Sb}_{2} \mathrm{~S}_{3} @ \mathrm{C}$ rods & $0.01-2.5$ & 100 & 730.5 & 100 & 95.7 & 3.2 & 429 & [97] \\
\hline Hollow-sphere $\mathrm{Sb}_{2} \mathrm{~S}_{3} / \mathrm{C}$ & $0.01-3.0$ & 200 & 693.4 & 100 & 80 & $3.2 / 6.4$ & $220 / 180$ & {$[100]$} \\
\hline Multi-shelled $\mathrm{Sb}_{2} \mathrm{~S}_{3}$ & $0.01-1.5$ & 1000 & 700 & 50 & 71.4 & $1 / 2$ & 198/116 & {$[104]$} \\
\hline $\mathrm{Sb}_{2} \mathrm{~S}_{3} @ \mathrm{MWCNTs}$ & $0.005-3$ & 50 & 451(10th) & 50 & 91.4 & 1 & 339.1 & {$[105]$} \\
\hline $\mathrm{Sb}_{2} \mathrm{~S}_{3} / \mathrm{SGS}$ & $0.01-2.5$ & 2000 & 631.8 & 900 & 83 & 5 & 591.6 & {$[106]$} \\
\hline $\mathrm{Sb}_{2} \mathrm{~S}_{3} /$ carbon-silicon oxide & $0.01-2.5$ & 200 & 321 & 200 & - & 5 & 221 & {$[107]$} \\
\hline $\mathrm{Sb}_{2} \mathrm{Se}_{3}$ ultra-long nanowires & $0.01-2$ & 100 & 360 & 50 & 80.3 & $0.8 / 1.6$ & $234 / 153$ & {$[111]$} \\
\hline $\mathrm{Sb}_{2} \mathrm{~S}_{3} / \mathrm{C}$ & $0.005-2$ & 200 & 577.8 & 100 & 93.1 & $1 / 2$ & $557 / 520$ & {$[112]$} \\
\hline $2 \mathrm{D} \mathrm{Sb}_{2} \mathrm{~S}_{3}$ & $0.01-3$ & 200 & 500 & 100 & - & 2 & 300 & {$[113]$} \\
\hline $\mathrm{Sb}_{2} \mathrm{~S}_{3} @ \mathrm{FeS}_{2} / \mathrm{rGO}$ & $0.1-3$ & 5000 & 534.8 & 1000 & 85.7 & 10 & 537.9 & {$[114]$} \\
\hline 2D layered $\mathrm{Sb}_{2} \mathrm{Se}_{3} / \mathrm{C}$ & $0-3$ & 50 & 407 & 50 & 92.9 & $1 \mathrm{C} / 3 \mathrm{C}$ & $323 / 270$ & {$[115]$} \\
\hline $\mathrm{Sb}_{2} \mathrm{Se}_{3} / \mathrm{CNFs}$ & $0.01-3$ & 1000 & 302.7 & 800 & - & 10 & 250 & {$[116]$} \\
\hline
\end{tabular}

RGO phase with mechanical flexibility can anchor the $\mathrm{SnSb}$ nanoparticles onto its surface. Such composition can effectively inhibit the agglomeration of $\mathrm{SnSb}$ alloy, thereby providing excellent conductivity to promote electron and ion transport and adjust the internal stress caused by volume change. The composite electrode exhibited a reversible capacity of 407 and $85 \mathrm{~mA} \cdot \mathrm{h} / \mathrm{g}$ at 5 and $30 \mathrm{C}$ (Fig. 11d), respectively, and maintained a reversible specific discharge capacity of $361 \mathrm{~mA} \cdot \mathrm{h} / \mathrm{g}$ over 80 cycles at $0.2 \mathrm{C}$. One of the key development goals of electrode materials is the self-supporting feature, which was also a goal of the development in Sb-based alloys. As shown in Fig. 11e, Han et al. [124] described an N-doped carbon nanofiber matrix with encapsulated CoSb nanoparticles through the electrospinning method. This self-supporting structure with pseudocapacitive behaviors could obtain fast kinetics and high first Coulombic efficiency for SIB anodes. The CoSb self-supporting structure exhibited a reversible capacity of $703,648,559,541,445$, and $386 \mathrm{~mA} \cdot \mathrm{h} / \mathrm{g}$ at 0.1 , $0.2,0.5,0.75,1.0$, and $2.0 \mathrm{~A} / \mathrm{g}$, respectively (Fig. 11f). Moreover, this composite electrode held a capacity of $413 \mathrm{~mA} \cdot \mathrm{h} / \mathrm{g}$ over 1000 cycles at $1 \mathrm{~A} / \mathrm{g}$. As another example, Wang et al. [125] reported a binder-free $\mathrm{Cu}_{2} \mathrm{Sb} / \mathrm{Cu}$ electrode via a replacement reaction. Testing of such a self-supporting-like structure with porous $\mathrm{Cu}_{2} \mathrm{Sb}$ nanoparticle film in SIBs revealed a $98.5 \%$ capacity retention rate retained over 200 cycles at $0.8 \mathrm{~A} / \mathrm{g}$.
Some research results revealed that $\mathrm{Sb}$-based bimetallic oxides, such as $\mathrm{Sb}_{2} \mathrm{MoO}_{6}$ [126] and $\mathrm{FeSbO}_{4}$ [127], can store more $\mathrm{Na}^{+}$via a continuous conversion and alloying reaction. In particular, because bismuth $(\mathrm{Bi})$ and $\mathrm{Sb}$ belong to the same main group in the periodic table of elements, and they have similar physical and chemical properties, $\mathrm{Bi}$ and $\mathrm{Sb}$ can form a Sb-Bi-based alloy at any molar ratio. In addition, the introduction of $\mathrm{Bi}$ into $\mathrm{Sb}$ can significantly extend the voltage platform and increase the specific capacity during charging and discharging processes $[17,120,128]$.

In summary, Table 4 lists a number of examples of Sbbased alloys as the anode in SIBs and the corresponding key performance metrics $[129,130]$. Because the electrochemical performance of most Sb-based alloy materials cannot match the performance of a metal Sb anode in SIBs, more breakthrough explorations are required to address this issue.

\section{Potassium-Ion Batteries}

\section{Metallic Antimony for Potassium-lon Batteries}

The PIB is another promising candidate to replace the highcost lithium-ion battery. Due to the similar reaction mechanism of PIBs and SIBs and the similar ionic radius of $\mathrm{K}^{+}$and $\mathrm{Na}^{+}$, many modification strategies for Sb-based materials 

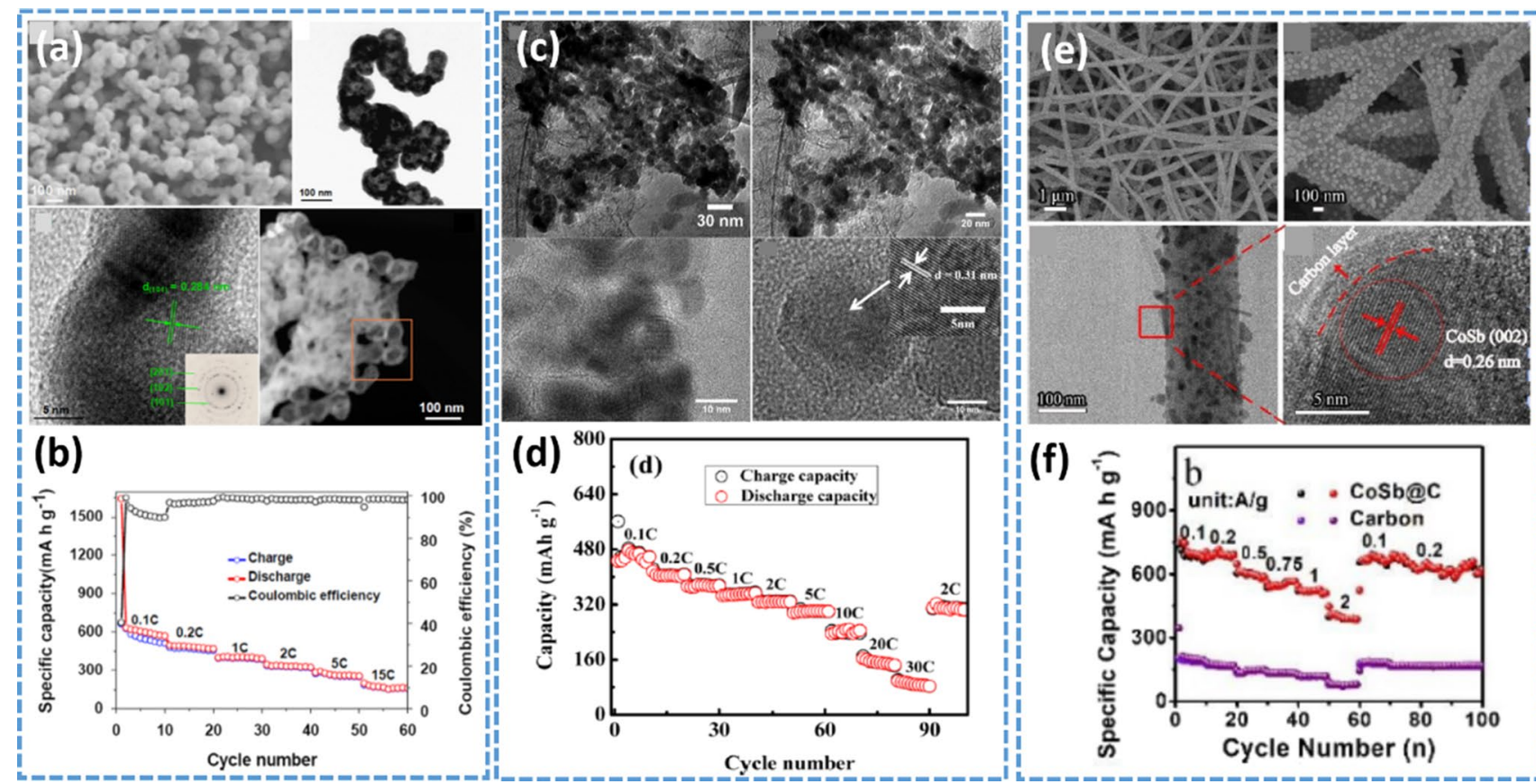

Fig. 11 a SEM and TEM images of 3D NiSb intermetallic hollow nanospheres, $\mathbf{b}$ rate capability of 3D NiSb intermetallic hollow nanospheres electrode materials at various current densities from 0.1 to 15 C. Reproduced with permission from Ref. [122]. Copyright 2015, Elsevier. c SEM and TEM images of SnSb alloy nanoparticles composite with RGO (RGO-SnSb), d rate capability of RGO-SnSb composites at various current densities from 0.1 to $30 \mathrm{C}$. Reproduced with permission from Ref. [123]. Copyright 2015, American Chemical Society. e SEM and TEM images and EDS mapping of self-supported N-doped carbon nanofibers encapsulated CoSb nanoparticles, f the corresponding rate performance of self-supported $\mathrm{N}$-doped carbon nanofibers encapsulated $\mathrm{CoSb}$ nanoparticles composites at various current densities from 0.1 to $2 \mathrm{~A} / \mathrm{g}$. Reproduced with permission from Ref. [124]. Copyright 2013, Royal Society of Chemistry

Table 4 Summary of the electrochemical performance of Sb-based alloy anodes for SIBs

\begin{tabular}{|c|c|c|c|c|c|c|c|c|}
\hline \multirow[t]{2}{*}{ Samples } & \multicolumn{5}{|c|}{ Cycle stability } & \multicolumn{2}{|l|}{ Rate capability } & \multirow[t]{2}{*}{ Ref } \\
\hline & Potential (V) & $\begin{array}{l}\text { Current } \\
\text { density } \\
(\mathrm{mA} / \mathrm{g})\end{array}$ & $\begin{array}{l}\text { Revers- } \\
\text { ible capacity } \\
(\mathrm{mAh} / \mathrm{g})\end{array}$ & Cycle number & $\begin{array}{l}\text { Capacity } \\
\text { retention } \\
(\%)\end{array}$ & $\begin{array}{l}\text { Current density } \\
\text { (A/g) }\end{array}$ & Capacity (mAh/g) & \\
\hline 3D SnSb@N-PG & $0.005-3$ & 10,000 & $\sim 190$ & 4000 & 100 & - & - & [51] \\
\hline $\mathrm{SnSb} / 3 \mathrm{D}-\mathrm{NPC}$ & $0-2$ & 5000 & 266.6 & 15,000 & - & $0.2 / 20$ & $793.4 / 359.1$ & [117] \\
\hline $\mathrm{Sb} / \mathrm{NiSb}$ & $0-2$ & 100 & 521 & 100 & 96 & $0.1 / 2$ & $567 / 279.7$ & [118] \\
\hline $\begin{array}{l}\mathrm{Zn} \text {-Sb intermetallic } \\
\text { nanowires }\end{array}$ & $0.01-2.0$ & 414 & - & 200 & - & $0.828 / 2.07$ & $247 / 187$ & [119] \\
\hline $\mathrm{BiSb}_{3} / \mathrm{C}$ & $0-2$ & 2000 & 233.2 & 2500 & 73.1 & $0.2 / 5$ & $405.3 / 249.9$ & [120] \\
\hline $\mathrm{Sn}-\mathrm{Ge}-\mathrm{Sb}$ & $0.01-2$ & 425 & 653 & 50 & 75.2 & 8.5 & 381 & [121] \\
\hline $\begin{array}{l}\text { 3D interconnected } \\
\text { NiSb hollow } \\
\text { nanospheres }\end{array}$ & $0.01-2$ & $10 \mathrm{C}$ & 230 & 150 & - & $5 \mathrm{C} / 15 \mathrm{C}$ & $300 / 201$ & [122] \\
\hline RGO-SnSb & $0.001-3$ & 100 & 391.5 & 80 & 92.3 & 1 & 330 & [123] \\
\hline $\begin{array}{l}\text { CoSb@C Nanofib- } \\
\text { ers }\end{array}$ & $0.01-3$ & 1000 & 413 & 1000 & - & $1 / 2$ & $445 / 386$ & [124] \\
\hline $\mathrm{Cu}_{2} \mathrm{Sb} / \mathrm{Cu}$ & $0.05-2$ & 800 & 270 & 200 & 98.5 & $2 / 4 / 8$ & $267.9 / 263.5 / 256.1$ & [125] \\
\hline $\mathrm{FeSbO}_{4}$ & $0.01-2.5$ & 200 & 200 & 200 & - & - & - & [127] \\
\hline $\mathrm{n}-\mathrm{MnSb}_{2} \mathrm{~S}_{4} / \mathrm{rGO}$ & $0-2.5$ & 2000 & 492.4 & 700 & 74.9 & $0.1 / 1$ & $953.7 / 472.9$ & [129] \\
\hline $\mathrm{SnSb} / \mathrm{N}-\mathrm{PCNW}$ & $0.01-2.5$ & 2000 & 180 & 10,000 & - & $0.05 / 10$ & $400 / 133$ & [130] \\
\hline
\end{tabular}


(e.g., metal Sb, oxide, sulfide, selenide, and alloy) have been used to enhance their performance as the anodes of PIBs. However, the Sb-based materials have encountered obstacles as an anode in PIBs that are similar to those of SIBs; these obstacles can be overcome by several classic strategies, such as coupling carbon material, introducing heteroatom dopants, combining with other conductive substrates, synthesizing specific structures, and employing specific electrolytes and binders [131-145].

In situ testing technology can reveal the in-depth reaction mechanisms in real time, thereby laying a solid foundation for a deeper understanding of the causes and processes of electrochemical reactions. The reaction mechanism of Sbbased materials has also been studied through the corresponding in situ process in PIBs, such as in situ XRD and in situ TEM [139, 142, 144]. As shown in Fig. 12a, Huang and co-workers[145] employed in situ TEM to reveal the reason that the yolk-shelled Sb-carbon nano-boxes located in the nanowire have an excellent stable cycle $(227 \mathrm{~mA} \bullet \mathrm{h} / \mathrm{g}$ after 1000 cycles at $1 \mathrm{~A} / \mathrm{g}$ ). The pore space derived from the $\mathrm{Sb}$ nanoparticles and their surrounding carbon effectively accommodates the entire volume change and maintains the structural integrity. Additionally, optimizing a suitable electrolyte is also beneficial to improving the performance of Sb-based PISs. Studies have found that different electrolytes are likely to have a diametrically opposite difference for the impact of the same material in K-storage [142]. As presented in Fig. 12b, Zhou et al. [143] improved the $\mathrm{K}$-storage ability of $\mathrm{Sb}$ alloy via electrolyte engineering. The electrolyte composition (anion, solvent, concentration, etc.) (a)

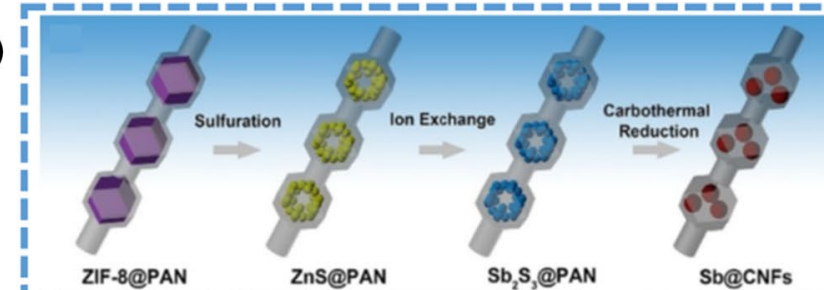

(b)
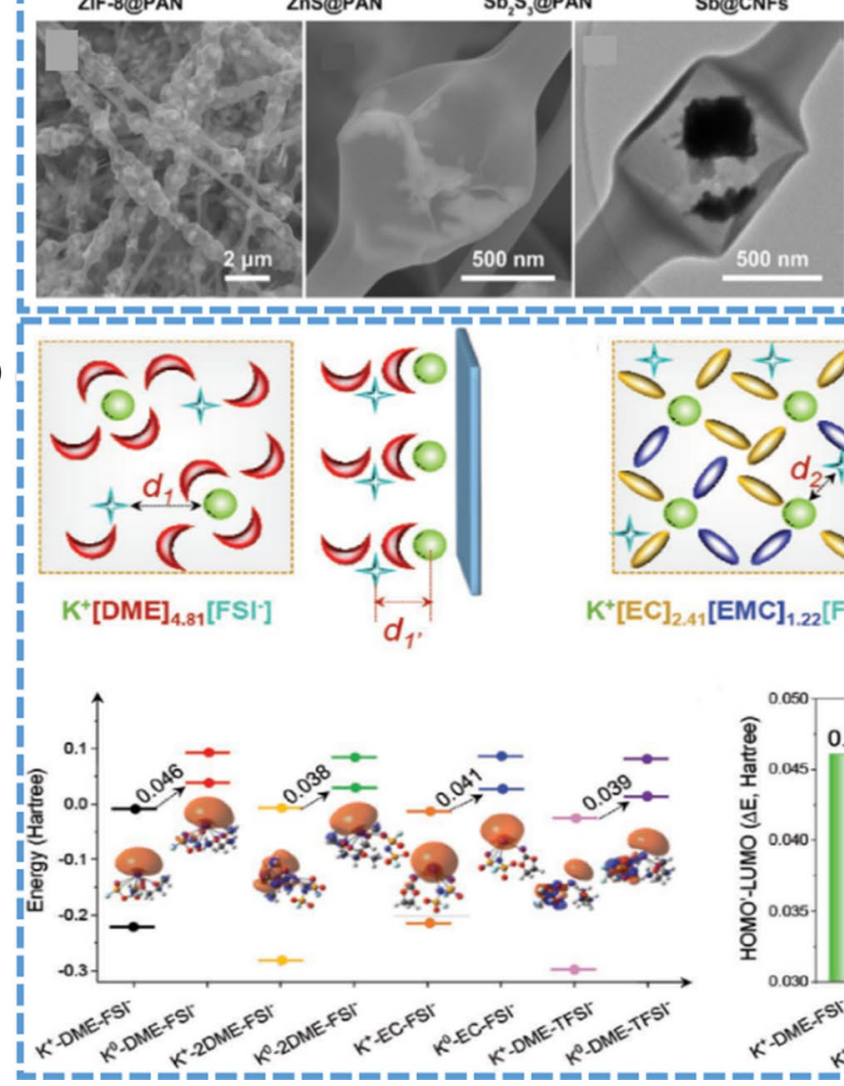

Fig. 12 a Illustration of the synthesis processes for Sb@CNFs, SEM images of Sb@CNFs at different magnifications, and TEM images of Sb@CNFs at different magnifications and the corresponding performance: the cycle at $200 \mathrm{~mA} / \mathrm{g}$ and the long-term cycle at $1000 \mathrm{~mA} / \mathrm{g}$.
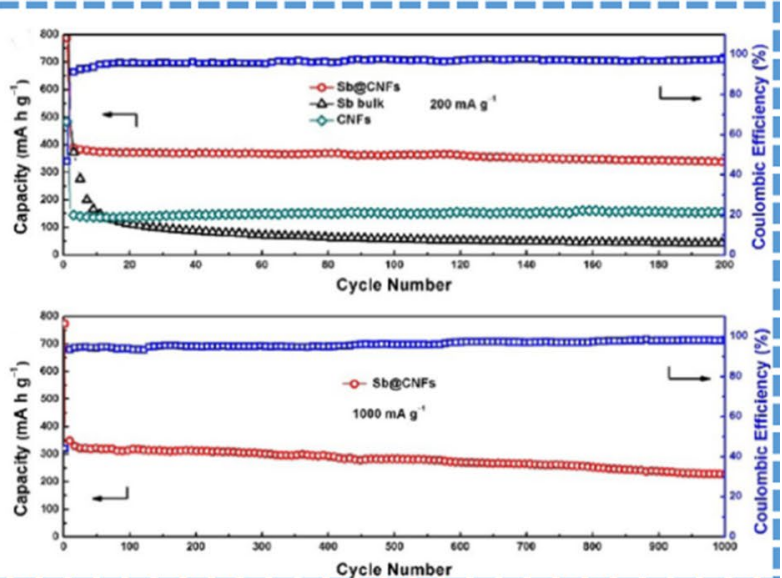

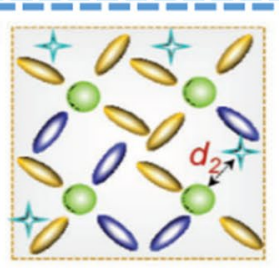

$\mathrm{K}^{+}[\mathrm{EC}]_{2,41}[\mathrm{EMC}]_{1.22}[\mathrm{FSI}]$

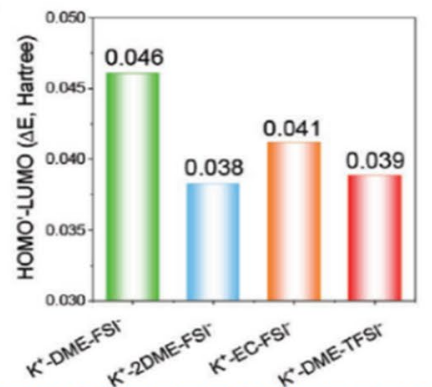

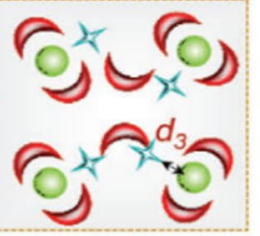

$\left.\mathrm{K}+{ }^{\mathrm{DME}}\right]_{2.41}\left[\mathrm{FSI}^{-}\right]$
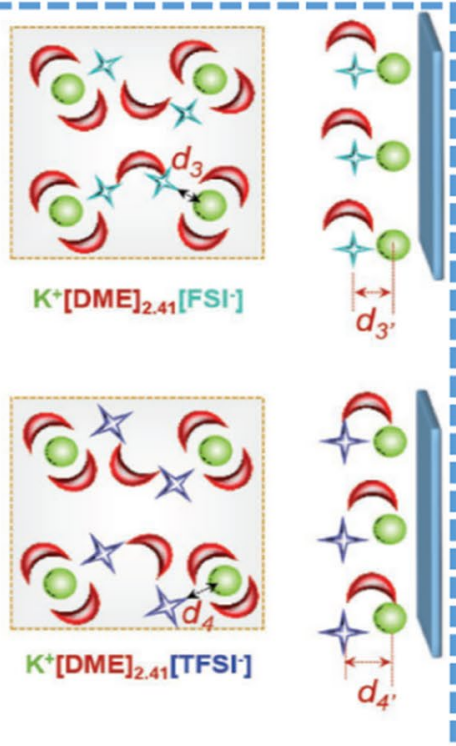

Reproduced with permission from Ref. [145]. Copyright 2020, John Wiley \& Sons, Inc. b Schematic illustration of the electrolyte analysis and interfacial model. Reproduced with permission from Ref. [143]. Copyright 2021, John Wiley \& Sons, Inc 
resulted in an excellent performance. Furthermore, the solvent type and anion species can affect the electronegativity of the $\mathrm{K}^{+}$-solvent-anion complex. As a result, the $\mathrm{Sb}$ anode without nano-structural engineering and carbon modification exhibited a high capacity of 628 and $305 \mathrm{~mA} \cdot \mathrm{h} / \mathrm{g}$ at current densities of 0.1 and $3 \mathrm{~A} / \mathrm{g}$, respectively, and remained stable over 200 cycles.

\section{Antimony Oxides for Potassium-Ion Batteries}

Although the specific mechanism of antimony oxides storing $\mathrm{K}$ ions has not been fully studied, this does not prevent us from using them as the anode of PIBs. For example, producing porous structures and introducing heteroatoms are universal approaches to improving the electrodes of PIBs. Recently, our group [141] successfully prepared core-shelled heterostructure $\mathrm{Sb} @ \mathrm{Sb}_{2} \mathrm{O}_{3}$ nanoparticles encapsulated in $\mathrm{N}$-doped hollow porous microspheres via spray drying and heat treatment procedures (Fig. 13). The carbon structure is porous and hollow, and the embedded nanoparticles have a heterogeneous interface between $\mathrm{Sb}$ and $\mathrm{Sb}_{2} \mathrm{O}_{3}$. The composite architecture showed an excellent rate (474 and $239 \mathrm{~mA} \cdot \mathrm{h} / \mathrm{g}$ at 0.1 and $5 \mathrm{~A} / \mathrm{g}$, respectively) and ultra-long stability $(10,000$ cycles at $2 \mathrm{~A} / \mathrm{g})$ as an anode for PIBs. It can be seen that the synergy between multiple effective strategies can often promote the energy storage application of micro-nano-composite materials in alkaline ion batteries. In this regard, determining how to adjust the balance between different modification systems and giving full play to their advantages will become a key factor in the improvement of PIBs anode materials.

\section{Antimony Sulfides/Selenides for Potassium-Ion Batteries (PIBs)}

As a member of a large family of Sb-based materials, the $\mathrm{Sb}$ chalcogenides are also studied in PIBs. For example, Yang and co-workers [135] produced $\mathrm{Sb}_{2} \mathrm{~S}_{3} / \mathrm{Sb}_{2} \mathrm{Se}_{3}$ nanodots/carbon composites via pyrolysis and co-sulfurization/ selenylation process. The $\mathrm{S}(\mathrm{Se})$-doped carbon matrix and ultra-small nanoparticles $\left(\mathrm{Sb}_{2} \mathrm{~S}_{3} / \mathrm{Sb}_{2} \mathrm{Se}_{3}\right)$ can synergistically increase the transport capacity of $\mathrm{K}^{+}$and alleviate volume expansion. As a result, the $\mathrm{Sb}_{2} \mathrm{Se}_{3}$ nanodots/carbon configuration exhibited a reversible capacity of $\sim 312 \mathrm{~mA} \bullet \mathrm{h} / \mathrm{g}$ over 200 cycles at $1 \mathrm{~A} / \mathrm{g}$ [135]. In addition, because 2D transition metal carbides, carbonitrides, and nitrides (named as MXene) have similar high conductivity and buffer function as carbonaceous materials, they are being adopted widely in the energy storage field. Regarding Sb-based materials in PIBs, Wang et al. [136] constructed self-assembled $\mathrm{Sb}_{2} \mathrm{~S}_{3}$ nanoflower composite MXene $\left(\mathrm{Ti}_{3} \mathrm{C}_{2}\right)$ flakes using a solvothermal and calcination process. Not surprisingly, the PIBs anode exhibited an outstanding rate performance of $102 \mathrm{~mA} \cdot \mathrm{h} / \mathrm{g}$ at $2 \mathrm{~A} / \mathrm{g}$ and maintained $79 \%$ capacity retention after 500 cycles at $100 \mathrm{~mA} / \mathrm{g}$. Lu and Chen [146] reported that the $\mathrm{Sb}_{2} \mathrm{~S}_{3}$ nanoparticles could be dispersed in $\mathrm{S}, \mathrm{N}$-doped graphene $\left(\mathrm{Sb}_{2} \mathrm{~S}_{3}\right.$-SNG) to form a self-supported anode for PIBs. Such nanoparticle architecture not only enhanced the electric conductivity and the mechanical stability but also greatly decreased the inactive weight of the electrode. When assembled with $\mathrm{KVPO}_{4} \mathrm{~F}-\mathrm{C}$, the obtained full cell achieved a high energy density of $166.3 \mathrm{~W} \bullet \mathrm{h} / \mathrm{kg}$.

As another element similar to $\mathrm{S}$, the antimonide of selenium (Se) should theoretically exhibit a similar potassium storage capacity. Qian et al. [147] demonstrated

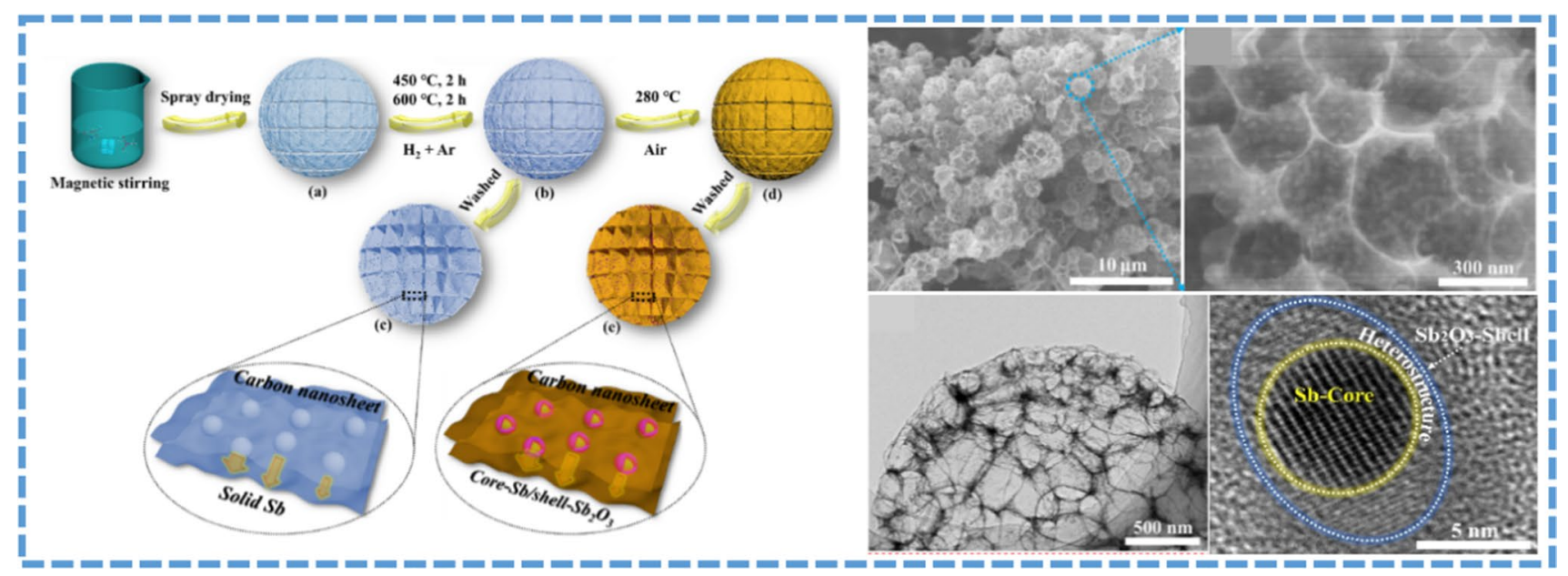

Fig. 13 Schematic illustration of the morphological and structural evolution process for $\mathrm{Sb} @ \mathrm{Sb}_{2} \mathrm{O}_{3} @ \mathrm{~N}-3 \mathrm{DCH}$ composite during the preparation, and corresponding SEM and TEM images of Sb@
$\mathrm{Sb}_{2} \mathrm{O}_{3} @ \mathrm{~N}-3 \mathrm{DCH}$ composite. Reproduced with permission from Ref. [141]. Copyright 2021, John Wiley \& Sons, Inc 
a self-templating method to fabricate the $\mathrm{Sb}_{2} \mathrm{Se}_{3} @ \mathrm{C}$ microtube. In this work, the hollow structure enabled the $\mathrm{Sb}_{2} \mathrm{Se}_{3} @ \mathrm{C}$ to present a capacity of $191.4 \mathrm{~mA} \cdot \mathrm{h} / \mathrm{g}$ at $500 \mathrm{~mA} / \mathrm{g}$ after 400 cycles as a PIB anode. The in situ Raman spectra indicated that $\mathrm{Sb}_{2} \mathrm{Se}_{3} @ \mathrm{C}$ storage $\mathrm{K}$ occurs via a conventional-alloying-type mechanism; the reaction can be described as:

$\mathrm{Sb}_{2} \mathrm{Se}_{3}+12 \mathrm{~K}^{+}+12 \mathrm{e}^{-} \leftrightarrow 3 \mathrm{~K}_{2} \mathrm{Se}+2 \mathrm{~K}_{3} \mathrm{Sb}(\mathrm{K}$ insertion $)$

$3 \mathrm{~K}_{2} \mathrm{Se}+2 \mathrm{~K}_{3} \mathrm{Sb} \leftrightarrow \mathrm{Sb}_{2} \mathrm{Se}_{3}+12 \mathrm{~K}^{+}+12 \mathrm{e}^{-}(\mathrm{K}$ extraction $)$

The volume change should be taken into account when designing the PIBs using $\mathrm{Sb}_{2} \mathrm{Se}_{3}$ as the anode. In this regard, researchers reported a strategy that applied the self-wrinkled RGO as the matrix to house tiny $\mathrm{Sb}_{2} \mathrm{Se}_{3}$ nanoparticles. When used in PIBs, the RGO with high elasticity acted as the buffer to relieve the volume expansion of $\mathrm{Sb}_{2} \mathrm{Se}_{3}$. As a result, the $\mathrm{Sb}_{2} \mathrm{Se}_{3} @ \mathrm{RGO}$ anode could retain the capacity of $203.4 \mathrm{~mA} \bullet \mathrm{h} / \mathrm{g}$ at $500 \mathrm{~mA} / \mathrm{g}$ [148].

\section{Antimony-Based Alloy for Potassium-Ion Batteries}

The preparation of Sb-based alloys is also conducive to improving the K-storage when used as battery electrodes. As a typical example, Xiong et al. [139] fabricated a composite porous nanosheet embedded with BiSb alloy nanoparticles through a freeze-drying and pyrolysis process (Fig. 14a, b). The porous two-dimensional carbon material, which effectively relieves the internal stress generated during the potassium storage process, delivered a specific capacity of $320 \mathrm{~mA} \cdot \mathrm{h} / \mathrm{g}$ over 600 cycles at $0.5 \mathrm{~A} / \mathrm{g}$. Furthermore, the anode electrode also exhibited excellent performance in potassium-ion full cells. Using $\mathrm{K}_{4} \mathrm{Fe}(\mathrm{CN})_{6}(\mathrm{KFC})$ as the cathode, the full cell (BiSb@C//KFC) showed a voltage plateau at $3.0 \mathrm{~V}$ and displayed a high capacity of $396 \mathrm{~mA} \cdot \mathrm{h} / \mathrm{g}$. Coincidentally, another project on salt template-directed pore formation was reported by Yang and co-workers (Fig. 14c) [140], in which a series of Swiss-cheese-like nitrogen-doped porous carbon embedded with $\mathrm{MSb}(\mathrm{M}=\mathrm{Ni}$, $\mathrm{Co}$, or $\mathrm{Fe}$ ) with $\mathrm{M}-\mathrm{N}-\mathrm{C}$ coordination (Fig. 14d) were generated. The CoSb electrodes presented super discharge capacities of 1214, 1016, 835, 701, 589, 458, and $343 \mathrm{~mA} \bullet \mathrm{h} / \mathrm{g}$ at $0.1,0.2,0.5,1,2,5$, and $10 \mathrm{~A} / \mathrm{g}$, respectively.

Finally, the related Sb-based materials used as electrodes in PIBs are summarized in Table 5 [149, 150]. Compared with SIBs anode, studies on Sb-based PIBs materials started later and are fewer in number. Therefore, more relevant research is needed, with much progress required before the emergence of self-supporting, highperformance $\mathrm{Sb}$-based electrodes for PIBs.

\section{Conclusion and Perspectives}

In this review, we summarized in detail the recent research progress of $\mathrm{Sb}$-based materials, ranging from metal to compounds to alloys, as anodes for SIBs/PIBs. Because these Sb-based materials suffer from the shortcomings of volume change and poor conductivity, we specifically highlighted the general strategies to address these shortcomings, such as reducing the size of Sb-based active materials, introducing carbon materials, designing the core-shelled or hollow structure, and utilizing other stable and conductive protection materials. According to the above strategies, many types of Sb-based materials with nanostructures and diversity morphologies have been reported. Benefit from the high conductivity, high porosity, large specific surface area of the hollow structure, and high degree of protection of the core-shelled structure, these Sb-based materials effectively achieve high-speed ion transfer and electron diffusion, alleviate the internal stress upon cycling, and even promote the penetration of electrolyte into the electrode. Thus, using these Sb-based materials, the specific capacity, the long-term cycle stability, and the rate doubling ability of the electrodes of SIBs/ PIBs are greatly improved.

Despite the achievements that have been achieved, challenges still exist in the aspect of exploring the mechanism of energy storage, improving the performance of actual devices, and enhancing the potential of large-scale applications.

First, in terms of the mechanism, the interaction of $\mathrm{Sb}$-based materials with $\mathrm{Na} / \mathrm{K}$ ions needs to be studied in depth. In particular, Sb oxides and alloy materials react in a complicated manner. Considering the cost, safety, test conditions, and other aspects, it is difficult to explore the reaction process of various materials. Therefore, it is of great significance to establish a reliable database that provides guidance for the effective search of candidate electrode materials and electrolytes; this database will help simplify the subsequent experimental procedures and costs. Moreover, to understand the "black box" mechanisms, researchers need closer in situ analysis methods and more in-depth physical theoretical models to meet this challenge [6, 11, 151-153]. Recently, widely used in situ techniques (such as in situ Raman spectroscopy, cryo-electron microscopy, and Fourier infrared spectroscopy) have been used to analyze not only the chemical composition of the SEI film but also the distribution of each element. Therefore, these techniques can be used to effectively help to investigate the side reactions and the role of each solvent in the recycling process. These results can guide us to adopt more effective electrolyte optimization strategies.

On the aspect of battery devices, the biggest problem is the gap between experimental research and practical 


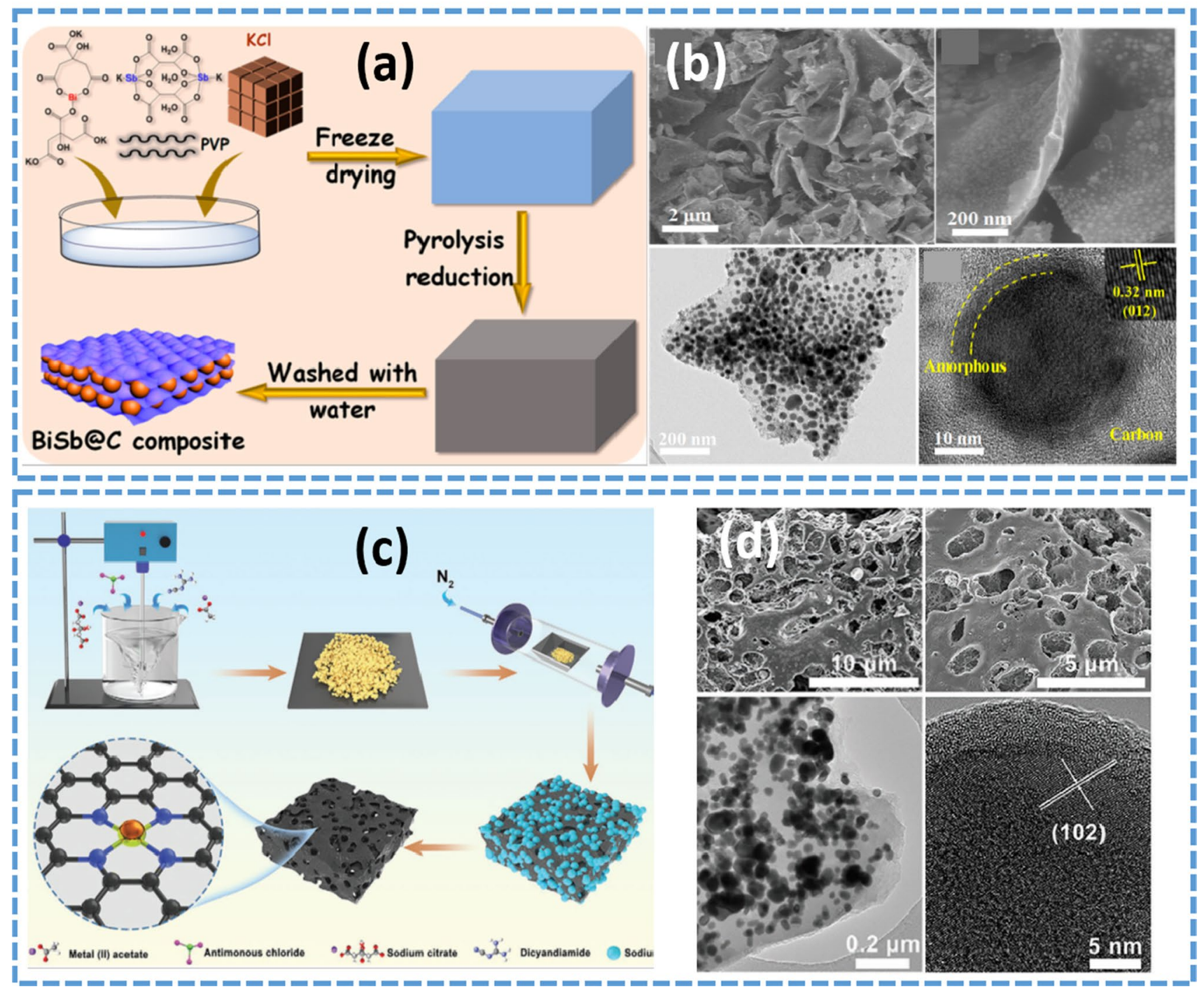

Fig. 14 a Schematic illustration of the synthesis process of BiSb@C composite, b SEM and TEM images of BiSb@C with 2D porous carbon nanosheet. Reproduced with permission from Ref. [139]. Copyright 2020, American Chemical Society. c Illustration of the fabrica- tion of MSb@NPC $(\mathrm{M}=\mathrm{Ni}, \mathrm{Co}$, or Fe) composites for LIBs, d SEM and TEM images of CoSb@NPC composite. Reproduced with permission from Ref. [140]. Copyright 2021, John Wiley \& Sons, Inc usage. For example, to the best of our knowledge, almost no Sb-based material has an initial Coulombic efficiency of more than $95 \%$. Furthermore, most of the reported Sbbased materials have not shown satisfied long cycle stability. The solution to this, it is necessary to pay more attention to study the full cell systems of SIBs and PIBs. We must strengthen the research of the mechanism to guide the matching design of the cathode and the anode. In addition, it is required to optimize the assembly process of the full cell so that the potential of Sb-based materials can be fully utilized. Furthermore, the optimization of the electrolyte is an important task for the development of high-performance SIBs/PIBs. For Sb-based electrodes, the suitable electrolyte should meet the following requirements: (1) ability to form a uniform and stable SEI layer; (2) stable chemical properties within the working voltage window.

In addition to the general issues, there are also some challenges under special conditions of use. For example, the high- and low-temperature sodium/potassium storage capacities are an indispensable basic requirement for large-scale fixed energy conversion equipment in the future. Although adequate high-temperature performance is relatively easy to achieve, there are few reports on the low-temperature sodium/potassium storage capacity of Sb-based materials. In contrast, our group studied the low-temperature Na storage behavior of Sb-based materials earlier and obtained relatively good low-temperature stability. Therefore, it will be a long-term opportunity and challenge to study the high/ 
Table 5 Summary of the electrochemical performance of Sb-based anode materials for PIBs

\begin{tabular}{|c|c|c|c|c|c|c|c|c|}
\hline \multirow[t]{2}{*}{ Samples } & \multicolumn{5}{|l|}{ Cycle stability } & \multicolumn{2}{|c|}{ Rate capability } & \multirow[t]{2}{*}{ Ref } \\
\hline & Potential (V) & $\begin{array}{l}\text { Current den- } \\
\text { sity }(\mathrm{mA} / \mathrm{g})\end{array}$ & $\begin{array}{l}\text { Revers- } \\
\text { ible capacity } \\
(\mathrm{mAh} / \mathrm{g})\end{array}$ & Cycle number & $\begin{array}{l}\text { Capacity } \\
\text { retention } \\
(\%)\end{array}$ & $\begin{array}{l}\text { Current } \\
\text { density } \\
(\mathrm{A} / \mathrm{g})\end{array}$ & Capacity (mAh/g) & \\
\hline u-Sb@CNFs & $0.01-3$ & 2000 & 188 & 3000 & 98.5 & $0.1 / 5$ & $465 / 145$ & {$[25]$} \\
\hline Sb-C-rGO & $0.001-1.5$ & 500 & 310 & 100 & 79 & $0.2 / 1.5$ & $388 / 195$ & [131] \\
\hline Sb@CN nanofibers & $0.01-2$ & 5000 & 212.7 & 1000 & - & $0.3 / 0.5$ & $324.7 / 243.6$ & [132] \\
\hline 3D Se@Sb@C & $0.001-2.5$ & 5000 & 166.6 & 5000 & 87 & $0.2 / 10$ & $365.6 / 107.7$ & [133] \\
\hline MS@C & $0.1-3$ & 2000 & 170.1 & 1000 & 73 & $0.1 / 2$ & $335.7 / 235.4$ & [134] \\
\hline $\mathrm{Sb}$ & $0-2$ & 200 & 553 & 200 & 95.4 & $0.1 / 3$ & $603 / 305$ & [143] \\
\hline $\mathrm{Sb} @ \mathrm{CNFs}$ & $0.01-2$ & 1000 & 227 & 1000 & - & $0.1 / 2$ & $448 / 121$ & [145] \\
\hline Sb@HCT & $0-3$ & 2000 & 300.1 & 120 & 73.5 & $0.1 / 5$ & $594.5 / 316.9$ & [150] \\
\hline $\mathrm{Sb} @ \mathrm{Sb}_{2} \mathrm{O}_{3} @ \mathrm{~N}-3 \mathrm{DCHs}$ & $0.005-3$ & 2000 & 319 & 10,000 & 100 & $0.1 / 5$ & $474 / 239$ & [141] \\
\hline $\mathrm{Sb}_{2} \mathrm{~S}_{3}-\mathrm{C} @ \mathrm{Nb}_{2} \mathrm{O}_{5}-\mathrm{C}$ & $0.01-3$ & 2000 & 96.1 & 2200 & 34 & 2 & 148.2 & {$[24]$} \\
\hline $\mathrm{Sb}_{2} \mathrm{~S}_{3} \mathrm{NDs} @ \mathrm{C}$ & $0.01-2$ & 1000 & 294.6 & 200 & - & $0.6 / 1.6$ & $436.6 / 200.6$ & [135] \\
\hline $\mathrm{Ti}_{3} \mathrm{C}_{2}-\mathrm{Sb}_{2} \mathrm{~S}_{3}$ & $0.01-2$ & 100 & 286 & 500 & 79 & $0.1 / 2$ & $357 / 102$ & [136] \\
\hline $\mathrm{Sb}_{2} \mathrm{~S}_{3}-\mathrm{rGO}$ & $0.01-2.1$ & 50 & 110 & 50 & 35 & - & - & [142] \\
\hline $\mathrm{Sb}_{2} \mathrm{~S}_{3} @ \mathrm{C}$ nanowires & $0.01-2.5$ & 50 & 293 & 50 & - & $0.05 / 1$ & $548 / 163$ & [144] \\
\hline $\mathrm{Bi}_{0.5} \mathrm{Sb}_{0.5} @ \mathrm{P}$ & $0.01-2$ & 1000 & 339.1 & 550 & - & 6.5 & 258.5 & {$[31]$} \\
\hline Sb-Co nanocomposites & $0.01-3$ & 60 & 402.7 & 100 & - & $0.06 / 6$ & $717.6 / 377.8$ & [137] \\
\hline CoSb@C nanofibers & $0.1-3$ & 1000 & 250 & 500 & - & $0.1 / 2$ & $490 / 160$ & [124] \\
\hline BiSb@C & $0.01-2.5$ & 500 & 320 & 600 & 97.5 & $0.05 / 2$ & $444.8 / 152$ & [139] \\
\hline SnSb LSM & $0-3$ & 500 & 296 & 150 & 90 & $0.1 / 5$ & $479 / 118$ & [138] \\
\hline $\mathrm{SnSb}_{2} \mathrm{Te}_{4} / \mathrm{G}$ & $0-2.5$ & 1000 & 478 & 1000 & 92.5 & $0.1 / 10$ & $574 / 373$ & [149] \\
\hline
\end{tabular}

low-temperature properties of Sb-based materials in SIBs/ PIBs.

Finally, we must also consider the issue of large-scale applications. The current methods to improve the energy storage performance of Sb-based materials include three aspects: (1) developing the potential of Sb itself, such as changing the alloy composition or building unique nanostructures [154]; (2) introducing composite materials, such as three-dimensional carbon [155, 156]; (3) improving additives, such as adhesives and conductive agents [157]. Indeed, most researchers focus on the structure and morphology modulation, whereas they ignore the feasibility of the preparation strategy in industrial production. Therefore, the development of a low-cost and large-scale synthesis strategy is another urgent need in the practical application of Sb-based materials.

Overall, we hope that this review serves as a reference for research on energy storage related to Sb-based materials and provides guidance for their future development.

Acknowledgements The authors gratefully acknowledge the financial support by the National Natural Science Foundation of China (Nos. 51771130, 51531004, and 51422104), the Tianjin Youth Talent Support Program, the Tianjin Natural Science Funds for Distinguished Young (No. 17JCJQJC44300), the Tianjin Science and Technology Support Project (No. 17ZXCLGX00060), and the China Postdoctoral Science Foundation (No. 2020M670649).

\section{Declarations}

Conflict of interest The authors declare that there is no conflict of interest.

Open Access This article is licensed under a Creative Commons Attribution 4.0 International License, which permits use, sharing, adaptation, distribution and reproduction in any medium or format, as long as you give appropriate credit to the original author(s) and the source, provide a link to the Creative Commons licence, and indicate if changes were made. The images or other third party material in this article are included in the article's Creative Commons licence, unless indicated otherwise in a credit line to the material. If material is not included in the article's Creative Commons licence and your intended use is not permitted by statutory regulation or exceeds the permitted use, you will need to obtain permission directly from the copyright holder. To view a copy of this licence, visit http://creativecommons.org/licenses/by/4.0/.

\section{References}

1. Dunn B, Kamath H, Tarascon JM (2011) Electrical energy storage for the grid: a battery of choices. Science 334(6058):928-935

2. Chen TM, Jin Y, Lv H et al (2020) Applications of lithium-ion batteries in grid-scale energy storage systems. Trans Tianjin Univ 26(3):208-217

3. Zhang LP, Wang W, Lu SF et al (2021) Carbon anode materials: a detailed comparison between Na-ion and K-ion batteries. Adv Energy Mater 11(11):2003640 
4. Deng JQ, Luo WB, Chou SL et al (2018) Sodium-ion batteries: from academic research to practical commercialization. Adv Energy Mater 8(4):1701428

5. Ong SP, Chevrier VL, Hautier G et al (2011) Voltage, stability and diffusion barrier differences between sodium-ion and lithium-ion intercalation materials. Energy Environ Sci 4:3680-3688

6. Min X, Xiao J, Fang MH et al (2021) Potassium-ion batteries: outlook on present and future technologies. Energy Environ Sci 14(4):2186-2243

7. Hu Z, Liu QN, Chou SL et al (2017) Advances and challenges in metal sulfides/selenides for next-generation rechargeable sodiumion batteries. Adv Mater 29(48):1700606

8. Li ZL, Zhao HL (2018) Recent developments of phosphorus-based anodes for sodium ion batteries. J Mater Chem A 6(47):24013-24030

9. Wang Y, Niu P, Li JZ et al (2021) Recent progress of phosphorus composite anodes for sodium/potassium ion batteries. Energy Storage Mater 34:436-460

10. Rajagopalan R, Tang YG, Ji XB et al (2020) Advancements and challenges in potassium ion batteries: a comprehensive review. Adv Funct Mater 30(12): 1909486

11. Imtiaz S, Amiinu IS, Xu Y et al (2021) Progress and perspectives on alloying-type anode materials for advanced potassiumion batteries. Mater Today

12. Sun T, Xie J, Guo W et al (2020) Covalent-organic frameworks: advanced organic electrode materials for rechargeable batteries. Adv Energy Mater 10(19):1904199

13. Chen B, Chao DL, Liu EZ et al (2020) Transition metal dichalcogenides for alkali metal ion batteries: engineering strategies at the atomic level. Energy Environ Sci 13(4):1096-1131

14. Wang AN, Hong WW, Yang L et al (2020) Bi-based electrode materials for alkali metal-ion batteries. Small 16(48):2004022

15. Song KM, Liu CT, Mi LW et al (2021) Recent progress on the alloy-based anode for sodium-ion batteries and potassium-ion batteries. Small 17(9):e1903194

16. Yang GR, Ilango PR, Wang SL et al (2019) Carbon-based alloytype composite anode materials toward sodium-ion batteries. Small 15(22):1900628

17. Lao MM, Zhang Y, Luo WB et al (2017) Alloy-based anode materials toward advanced sodium-ion batteries. Adv Mater 29(48): 1700622

18. Loaiza LC, Monconduit L, Seznec V (2020) Si and Ge-based anode materials for $\mathrm{Li}_{-}, \mathrm{Na}-$, and $\mathrm{K}$-ion batteries: a perspective from structure to electrochemical mechanism. Small 16(5): 1905260

19. Lu YY, Zhang N, Jiang S et al (2017) High-capacity and ultrafast Na-ion storage of a self-supported 3D porous antimony persulfide-graphene foam architecture. Nano Lett 17(6):3668-3674

20. Sarkar S, Peter SC (2021) An overview on Sb-based intermetallics and alloys for sodium-ion batteries: trends, challenges and future prospects from material synthesis to battery performance. J Mater Chem A 9(9):5164-5196

21. Tesfamhret Y, Carboni M, Asfaw HD et al (2021) Revealing capacity fading in Sb-based anodes using symmetric sodium-ion cells. J Phys Mater 4(2):024007

22. He M, Kravchyk K, Walter M et al (2014) Monodisperse antimony nanocrystals for high-rate $\mathrm{Li}$-ion and $\mathrm{Na}$-ion battery anodes: nano versus bulk. Nano Lett 14(3):1255-1262

23. Yang KX, Tang JF, Liu Y et al (2020) Controllable synthesis of peapod-likeSb@C and corn-like C@Sb nanotubes for sodium storage. ACS Nano 14(5):5728-5737

24. Liu HQ, He YN, Cao KZ et al (2021) Stimulating the reversibility of $\mathrm{Sb}_{2} \mathrm{~S}_{3}$ anode for high-performance potassium-ion batteries. Small 17(10):2008133

25. Ge XF, Liu SH, Qiao M et al (2019) Enabling superior electrochemical properties for highly efficient potassium storage by impregnating ultrafine $\mathrm{Sb}$ nanocrystals within nanochannel-containing carbon nanofibers. Angew Chem Int Ed 58(41):14578-14583

26. Wu ZB, Johannessen B, Zhang WC et al (2019) In situ incorporation of nanostructured antimony in an $\mathrm{N}$-doped carbon matrix for advanced sodium-ion batteries. J Mater Chem A 7(20): $12842-12850$

27. Duan J, Zhang W, Wu C et al (2015) Self-wrapped Sb/C nanocomposite as anode material for high-performance sodium-ion batteries. Nano Energy 16:479-487

28. Li W, Zhou M, Li H et al (2015) A high performance sulfurdoped disordered carbon anode for sodium ion batteries. Energy Environ Sci 8:2916-2921

29. Niu FE, Yang J, Wang NN et al (2017) $\mathrm{MoSe}_{2}$-covered N, P-doped carbon nanosheets as a long-life and high-rate anode material for sodium-ion batteries. Adv Funct Mater 27(23): 1700522

30. Xu JT, Wang M, Wickramaratne NP et al (2015) High-performance sodium ion batteries based on a 3D anode from nitrogendoped graphene foams. Adv Mater 27(12):2042-2048

31. Chen KT, Tuan HY (2020) Bi-Sb nanocrystals embedded in phosphorus as high-performance potassium ion battery electrodes. ACS Nano 14(9):11648-11661

32. Dong SH, Li CX, Li ZQ et al (2019) Synergistic effect of porous phosphosulfide and antimony nanospheres anchored on 3D carbon foam for enhanced long-life sodium storage performance. Energy Storage Mater 20:446-454

33. Ding J, Zhang H, Fan WJ et al (2020) Review of emerging potassium-sulfur batteries. Adv Mater 32(23):1908007

34. Xin S, Yin YX, Guo YG et al (2014) A high-energy room-temperature sodium-sulfur battery. Adv Mater 26(8):1261-1265

35. Hou HS, Jing MJ, Yang YC et al (2015) Antimony nanoparticles anchored on interconnected carbon nanofibers networks as advanced anode material for sodium-ion batteries. J Power Sour 284:227-235

36. Wu L, Lu HY, Xiao LF et al (2015) Electrochemical properties and morphological evolution of pitaya-like Sb@C microspheres as high-performance anode for sodium ion batteries. J Mater Chem A 3(10):5708-5713

37. Ares P, Palacios JJ, Abellán G et al (2018) Recent progress on antimonene: a new bidimensional material. Adv Mater 30(2):1703771

38. Yang J, Li JB, Wang TY et al (2021) Novel hybrid of amorphous $\mathrm{Sb} / \mathrm{N}$-doped layered carbon for high-performance sodium-ion batteries. Chem Eng J 407:127169

39. Tian W, Zhang S, Huo C et al (2018) Few-layer antimonene: anisotropic expansion and reversible crystalline-phase evolution enable large-capacity and long-life Na-ion batteries. ACS Nano 12(2):1887-1893

40. Song JH, Xiao DD, Jia HP et al (2018) A comparative study of pomegranate $\mathrm{Sb} @ \mathrm{C}$ yolk-shell microspheres as Li and $\mathrm{Na}$-ion battery anodes. Nanoscale 11(1):348-355

41. Wang N, Bai Z, Qian Y et al (2017) One-dimensional yolk-shell $\mathrm{Sb} @$ Ti-O-P nanostructures as a high-capacity and high-rate anode material for sodium ion batteries. ACS Appl Mater Interfaces 9(1):447-454

42. Xie F, Zhang L, Ye C et al (2019) The application of hollow structured anodes for sodium-ion batteries: from simple to complex systems. Adv Mater 31(38):e1800492

43. Song JH, Yan PF, Luo LL et al (2017) Yolk-shell structured $\mathrm{Sb} @ \mathrm{C}$ anodes for high energy Na-ion batteries. Nano Energy 40:504-511

44. Luo W, Li F, Gaumet JJ et al (2018) Bottom-up confined synthesis of nanorod-in-nanotube structured Sb@ N-C for durable lithium and sodium storage. Adv Energy Mater 8(19):1703237 
45. Chen BC, Qin HY, Li K et al (2019) Yolk-shelled Sb@C nanoconfined nitrogen/sulfur co-doped 3D porous carbon microspheres for sodium-ion battery anode with ultralong high-rate cycling. Nano Energy 66:104133

46. Liu Y, Zhou B, Liu S et al (2019) Galvanic replacement synthesis of highly uniform Sb nanotubes: reaction mechanism and enhanced sodium storage performance. ACS Nano 13(5):5885-5892

47. Wang NN, Bai ZC, Qian YT et al (2016) Double-walled Sb@ $\mathrm{TiO}_{2-x}$ nanotubes as a superior high-rate and ultralong-lifespan anode material for Na-ion and Li-ion batteries. Adv Mater 28(21):4126-4133

48. Liu J, Yu L, Wu C et al (2017) New nanoconfined galvanic replacement synthesis of hollow Sb@C yolk-shell spheres constituting a stable anode for high-rate $\mathrm{Li} / \mathrm{Na}$-ion batteries. Nano Lett 17(3):2034-2042

49. Liu Z, Yu X-Y, Lou XW et al (2016) Sb@C coaxial nanotubes as a superior long-life and high-rate anode for sodium ion batteries. Energy Environ Sci 9:2314-2318

50. He CN, Wu S, Zhao NQ et al (2013) Carbon-encapsulated $\mathrm{Fe}_{3} \mathrm{O}_{4}$ nanoparticles as a high-rate lithium ion battery anode material. ACS Nano 7(5):4459-4469

51. Qin J, Wang TS, Liu DY et al (2018) A top-down strategy toward $\mathrm{SnSb}$ in-plane nanoconfined 3D N-doped porous graphene composite microspheres for high performance Na-ion battery anode. Adv Mater 30(9): 1704670

52. Xu AD, Xia Q, Zhang SK et al (2019) Ultrahigh rate performance of hollow antimony nanoparticles impregnated in open carbon boxes for sodium-ion battery under elevated temperature. Small 15(45): 1903521

53. Kong M, Liu Y, Zhou B et al (2020) Rational design of Sb@C@ $\mathrm{TiO}_{2}$ triple-shell nanoboxes for high-performance sodium-ion batteries. Small 16(43):2001976

54. Lee Y, Lee KY, Choi W (2017) One-pot synthesis of antimonyembedded silicon oxycarbide materials for high-performance sodium-ion batteries. Adv Funct Mater 27(43): 1702607

55. Xu X, Dou ZF, Gu EL et al (2017) Uniformly-distributed Sb nanoparticles in ionic liquid-derived nitrogen-enriched carbon for highly reversible sodium storage. J Mater Chem A 5(26):13411-13420

56. Wu TJ, Hou HS, Zhang CY et al (2017) Antimony anchored with nitrogen-doping porous carbon as a high-performance anode material for Na-ion batteries. ACS Appl Mater Interfaces 9(31):26118-26125

57. Fang YY, Xu X, Du YC et al (2018) Novel nitrogen-doped reduced graphene oxide-bonded $\mathrm{Sb}$ nanoparticles for improved sodium storage performance. J Mater Chem A 6(24):11244-11251

58. Cui CY, Xu JT, Zhang YQ et al (2019) Antimony nanorod encapsulated in cross-linked carbon for high-performance sodium ion battery anodes. Nano Lett 19(1):538-544

59. Yu LT, Zhang LG, Fu JJ et al (2021) Hierarchical tiny-Sb encapsulated in MOFs derived-carbon and $\mathrm{TiO}_{2}$ hollow nanotubes for enhanced $\mathrm{Li} / \mathrm{Na}$-ion half-and full-cell batteries. Chem Eng J 417:129106

60. Fan XY, Han JX, Ding YL et al (2019) 3D nanowire arrayed Cu current collector toward homogeneous alloying anode deposition for enhanced sodium storage. Adv Energy Mater 9(28):1900673

61. Li XY, Sun ML, Ni JF et al (2019) Template-free construction of self-supported $\mathrm{Sb}$ prisms with stable sodium storage. Adv Energy Mater 9(24):1901096

62. Wang GH, Xiong XH, Lin ZH et al (2017) Sb/C composite as a high-performance anode for sodium ion batteries. Electrochim Acta 242:159-164

63. Kim D, Hwang C, Jeong J et al (2019) Bipolymer-cross-linked binder to improve the reversibility and kinetics of sodiation and desodiation of antimony for sodium-ion batteries. ACS Appl Mater Interfaces 11(46):43039-43045

64. Zhu Y, Han X, Xu Y et al (2013) Electrospun Sb/C fibers for a stable and fast sodium-ion battery anode. ACS Nano 7(7):6378-6386

65. Qiu S, Wu X, Xiao L et al (2016) Antimony nanocrystals encapsulated in carbon microspheres synthesized by a facile self-catalyzing solvothermal method for high-performance sodium-ion battery anodes. ACS Appl Mater Interfaces 8(2):1337-1343

66. Zhang N, Liu YC, Lu YY et al (2015) Spherical nano-Sb@C composite as a high-rate and ultra-stable anode material for sodium-ion batteries. Nano Res 8(10):3384-3393

67. Liu XY, Tian Y, Cao XQ et al (2018) Aerosol-assisted synthesis of spherical $\mathrm{Sb} / \mathrm{C}$ composites as advanced anodes for lithium ion and sodium ion batteries. ACS Appl Energy Mater 1(11):6381-6387

68. Zhang W, Liu Y, Chen C et al (2015) Flexible and binder-free electrodes of $\mathrm{Sb} / \mathrm{rGO}$ and $\mathrm{Na}_{3} \mathrm{~V}_{2}\left(\mathrm{PO}_{4}\right)_{3} / \mathrm{rGO}$ nanocomposites for sodium-ion batteries. Small 11(31):3822-3829

69. Wu TJ, Zhang CY, Hou HS et al (2018) Dual functions of potassium antimony(III)-tartrate in tuning antimony/carbon composites for long-life Na-ion batteries. Adv Func Mater 28(10): 1705744

70. Wang J, Yang J, Yin W et al (2017) Carbon-coated graphene/ antimony composite with a sandwich-like structure for enhanced sodium storage. J Mater Chem A 5:20623-20630

71. Liang LY, Xu Y, Li YL et al (2017) Facile synthesis of hierarchical fern leaf-like $\mathrm{Sb}$ and its application as an additivefree anode for fast reversible Na-ion storage. J Mater Chem A 5(4):1749-1755

72. Zhu MN, Kong XZ, Yang HL et al (2018) One-dimensional coaxial $\mathrm{Sb}$ and carbon fibers with enhanced electrochemical performance for sodium-ion batteries. Appl Surf Sci 428:448-454

73. Pham XM, Ngo DT, Le HTT et al (2018) A self-encapsulated porous $\mathrm{Sb}-\mathrm{C}$ nanocomposite anode with excellent $\mathrm{Na}$-ion storage performance. Nanoscale 10(41):19399-19408

74. Zhou X, Zhong Y, Yang M et al (2014) Sb nanoparticles decorated $\mathrm{N}$-rich carbon nanosheets as anode materials for sodium ion batteries with superior rate capability and long cycling stability. Chem Commun (Camb) 50(85):12888-12891

75. Li N, Liao S, Sun Y et al (2015) Uniformly dispersed self-assembled growth of $\mathrm{Sb}_{2} \mathrm{O}_{3} / \mathrm{Sb} @$ graphene nanocomposites on a 3D carbon sheet network for high Na-storage capacity and excellent stability. J Mater Chem A 3(11):5820-5828

76. Zhou XS, Liu X, Xu Y et al (2014) An $\mathrm{SbO}_{x}$ /reduced graphene oxide composite as a high-rate anode material for sodium-ion batteries. J Phys Chem C 118(41):23527-23534

77. Li W, Wang KL, Cheng SJ et al (2017) A two-dimensional hybrid of $\mathrm{SbO}_{x}$ nanoplates encapsulated by carbon flakes as a high performance sodium storage anode. J Mater Chem A 5(3):1160-1167

78. Yi Z, Han QG, Li X et al (2017) Two-step oxidation of bulk Sb to one-dimensional $\mathrm{Sb}_{2} \mathrm{O}_{4}$ submicron-tubes as advanced anode materials for lithium-ion and sodium-ion batteries. Chem Eng J 315:101-107

79. Zhou XZ, Zhang ZF, Lv X et al (2018) Facile and rapid synthesis of $\mathrm{Sb}_{2} \mathrm{O}_{3} / \mathrm{CNTs} / \mathrm{rGO}$ nanocomposite with excellent sodium storage performances. Mater Lett 213:201-203

80. Li DS, Yan D, Ma JQ et al (2016) One-step microwave-assisted synthesis of $\mathrm{Sb}_{2} \mathrm{O}_{3}$ /reduced graphene oxide composites as advanced anode materials for sodium-ion batteries. Ceram Int 42(14):15634-15642

81. Wang GZ, Feng JM, Dong L et al (2017) Antimony (IV) oxide nanorods/reduced graphene oxide as the anode material of sodium-ion batteries with excellent electrochemical performance. Electrochim Acta 240:203-214 
82. Guo X, Xie XQ, Choi S et al (2017) $\mathrm{Sb}_{2} \mathrm{O}_{3} / \mathrm{MXene}\left(\mathrm{Ti}_{3} \mathrm{C}_{2} \mathrm{~T}_{x}\right.$ ) hybrid anode materials with enhanced performance for sodiumion batteries. J Mater Chem A 5(24):12445-12452

83. Hong KS, Nam DH, Lim SJ et al (2015) Electrochemically synthesized $\mathrm{Sb} / \mathrm{Sb}_{2} \mathrm{O}_{3}$ composites as high-capacity anode materials utilizing a reversible conversion reaction for $\mathrm{Na}$-ion batteries. ACS Appl Mater Interfaces 7(31):17264-17271

84. Pan J, Wang NN, Zhou YL et al (2017) Simple synthesis of a porous $\mathrm{Sb} / \mathrm{Sb}_{2} \mathrm{O}_{3}$ nanocomposite for a high-capacity anode material in Na-ion batteries. Nano Res 10(5):1794-1803

85. Nam DH, Hong KS, Lim SJ et al (2015) High-performance Sb/ $\mathrm{Sb}_{2} \mathrm{O}_{3}$ anode materials using a polypyrrole nanowire network for Na-ion batteries. Small 11(24):2885-2892

86. Fei J, Cui YL, Li JY et al (2017) A flexible $\mathrm{Sb}_{2} \mathrm{O}_{3}$ carbon cloth composite as a free-standing high performance anode for sodium ion batteries. Chem Commun Camb Engl 53(98):13165-13167

87. Hu M, Jiang Y, Sun W et al (2014) Reversible conversionalloying of $\mathrm{Sb}_{2} \mathrm{O}_{3}$ as a high-capacity, high-rate, and durable anode for sodium ion batteries. ACS Appl Mater Interfaces 6(21):19449-19455

88. Kim S, Qu S, Zhang R et al (2019) High volumetric and gravimetric capacity electrodeposited mesostructured $\mathrm{Sb}_{2} \mathrm{O}_{3}$ sodium ion battery anodes. Small 15(23):e1900258

89. Sun Q, Ren QQ, Li H et al (2011) High capacity $\mathrm{Sb}_{2} \mathrm{O}_{4}$ thin film electrodes for rechargeable sodium battery. Electrochem Commun 13(12):1462-1464

90. Yang LP, Huang YL, Li XY et al (2018) Micro/nanostructuredependent electrochemical performances of $\mathrm{Sb}_{2} \mathrm{O}_{3}$ micro-bundles as anode materials for sodium-ion batteries. ChemElectroChem 5(18):2522-2527

91. Yu DY, Prikhodchenko PV, Mason CW et al (2013) Highcapacity antimony sulphide nanoparticle-decorated graphene composite as anode for sodium-ion batteries. Nat Commun 4:2922

92. Yao SS, Cui J, Lu ZH et al (2017) Unveiling the unique phase transformation behavior and sodiation kinetics of $1 \mathrm{D}$ van der Waals $\mathrm{Sb}_{2} \mathrm{~S}_{3}$ anodes for sodium ion batteries. Adv Energy Mater 7(8): 1602149

93. Zhao Y, Manthiram A (2015) Amorphous $\mathrm{Sb}_{2} \mathrm{~S}_{3}$ embedded in graphite: a high-rate, long-life anode material for sodium-ion batteries. Chem Commun 51:13205-13208

94. Li W, Zhou M, Li HM et al (2015) Carbon-coated $\mathrm{Sb}_{2} \mathrm{Se}_{3}$ composite as anode material for sodium ion batteries. Electrochem Commun 60:74-77

95. Choi JH, Ha CW, Choi HY et al (2016) $\mathrm{Sb}_{2} \mathrm{~S}_{3}$ embedded in amorphous $\mathrm{P} / \mathrm{C}$ composite matrix as high-performance anode material for sodium ion batteries. Electrochim Acta 210:588-595

96. Hwang SM, Kim J, Kim Y et al (2016) Na-ion storage performance of amorphous $\mathrm{Sb}_{2} \mathrm{~S}_{3}$ nanoparticles: anode for Naion batteries and seawater flow batteries. J Mater Chem A 4:17946-17951

97. Hou HS, Jing MJ, Huang ZD et al (2015) One-dimensional rodlike $\mathrm{Sb}_{2} \mathrm{~S}_{3}$-based anode for high-performance sodium-ion batteries. ACS Appl Mater Interfaces 7(34):19362-19369

98. Ou X, Yang CH, Xiong XH et al (2017) A new rGO-overcoated $\mathrm{Sb}_{2} \mathrm{Se}_{3}$ nanorods anode for $\mathrm{Na}^{+}$battery: in situ X-ray diffraction study on a live sodiation/desodiation process. Adv Funct Mater 27(13): 1606242

99. Zhao WX, Li CM (2017) Mesh-structured N-doped graphene@ $\mathrm{Sb}_{2} \mathrm{Se}_{3}$ hybrids as an anode for large capacity sodium-ion batteries. J Colloid Interface Sci 488:356-364

100. Ge P, Hou HS, Ji XB et al (2018) Enhanced stability of sodium storage exhibited by carbon coated $\mathrm{Sb}_{2} \mathrm{~S}_{3}$ hollow spheres. Mater Chem Phys 203:185-192
101. Park SK, Lee JK, Kang YC (2018) Yolk-shell structured assembly of bamboo-like nitrogen-doped carbon nanotubes embedded with Co nanocrystals and their application as cathode material for Li-S batteries. Adv Funct Mater 28(18): 1705264

102. Wang NN, Xu X, Liao T et al (2018) Boosting sodium storage of double-shell sodium titanate microspheres constructed from 2D ultrathin nanosheets via sulfur doping. Adv Mater 30(49): 1804157

103. Xie FX, Zhang L, Chen B et al (2019) Revealing the origin of improved reversible capacity of dual-shell bismuth boxes anode for potassium-ion batteries. Matter 1(6):1681-1693

104. Xie FX, Zhang L, Gu QF et al (2019) Multi-shell hollow structured $\mathrm{Sb}_{2} \mathrm{~S}_{3}$ for sodium-ion batteries with enhanced energy density. Nano Energy 60:591-599

105. Li JB, Yan D, Zhang XJ et al (2017) In situ growth of $\mathrm{Sb}_{2} \mathrm{~S}_{3}$ on multiwalled carbon nanotubes as high-performance anode materials for sodium-ion batteries. Electrochim Acta 228:436-446

106. Xiong $\mathrm{XH}$, Wang GH, Lin YW et al (2016) Enhancing sodium ion battery performance by strongly binding nanostructured $\mathrm{Sb}_{2} \mathrm{~S}_{3}$ on sulfur-doped graphene sheets. ACS Nano 10(12):10953-10959

107. Xie JJ, Xia J, Yuan YT et al (2019) $\mathrm{Sb}_{2} \mathrm{~S}_{3}$ embedded in carbonsilicon oxide nanofibers as high-performance anode materials for lithium-ion and sodium-ion batteries. J Power Sour 435:226762

108. Gui QY, Ba DL, Zhao ZS et al (2019) Synergistic coupling of ether electrolyte and 3D electrode enables titanates with extraordinary Coulombic efficiency and rate performance for sodiumion capacitors. Small Methods 3(2): 1800371

109. Hou BH, Wang YY, Ning QL et al (2019) Self-supporting, flexible, additive-free, and scalable hard carbon paper self-interwoven by 1D microbelts: superb room/low-temperature sodium storage and working mechanism. Adv Mater 31(40):e1903125

110. Xiao LF, Lu HY, Fang YJ et al (2018) Low-defect and low-porosity hard carbon with high coulombic efficiency and high capacity for practical sodium ion battery anode. Adv Energy Mater $8(20): 1703238$

111. Luo W, Calas A, Tang CJ et al (2016) Ultralong $\mathrm{Sb}_{2} \mathrm{Se}_{3}$ nanowire-based free-standing membrane anode for lithium/sodium ion batteries. ACS Appl Mater Interfaces 8(51):35219-35226

112. Choi JH, Ha CW, Choi HY et al (2017) High performance of $\mathrm{Sb}_{2} \mathrm{~S}_{3}$ /carbon composite with tailored artificial interface as an anode material for sodium ion batteries. Met Mater Int 23(6):1241-1249

113. Nam KH, Park CM (2019) $2 \mathrm{D}$ layered $\mathrm{Sb}_{2} \mathrm{Se}_{3}$-based amorphous composite for high-performance $\mathrm{Li}$ - and $\mathrm{Na}$-ion battery anodes. J Power Sour 433:126639

114. Chao L, Gao XW, Zhang B et al (2020) Bimetallic sulfide $\mathrm{Sb}_{2} \mathrm{~S}_{3} @ \mathrm{FeS}_{2}$ hollow nanorods as high performance anode materials for sodium-ion batteries. ACS Nano 14(3):3610-3620

115. Yao SS, Cui J, Deng Y et al (2019) Ultrathin $\mathrm{Sb}_{2} \mathrm{~S}_{3}$ nanosheet anodes for exceptional pseudocapacitive contribution to multibattery charge storage. Energy Storage Mater 20:36-45

116. Xia L, Yang Z, Tang B et al (2021) Carbon nanofibers with embedded $\mathrm{Sb}_{2} \mathrm{Se}_{3}$ nanoparticles as highly reversible anodes for Na-ion batteries. Small 17(4):e2006016

117. Li C, Pei YR, Zhao M et al (2021) Sodium storage performance of ultrasmall SnSb nanoparticles. Chem Eng J 420:129617

118. Zheng XM, You JH, Fan JJ et al (2020) Electrodeposited binderfree $\mathrm{Sb} / \mathrm{NiSb}$ anode of sodium-ion batteries with excellent cycle stability and rate capability and new insights into its reaction mechanism by operando XRD analysis. Nano Energy 77:105123

119. Nie AM, Gan LY, Cheng YC et al (2016) Ultrafast and highly reversible sodium storage in zinc-antimony intermetallic nanomaterials. Adv Funct Mater 26(4):543-552 
120. Guo ST, Li H, Lu Y et al (2020) Lattice softening enables highly reversible sodium storage in anti-pulverization $\mathrm{Bi}-\mathrm{Sb}$ alloy/carbon nanofibers. Energy Storage Mater 27:270-278

121. Farbod B, Cui K, Kalisvaart WP et al (2014) Anodes for sodium ion batteries based on tin-germanium-antimony alloys. ACS Nano 8(5):4415-4429

122. Liu J, Yang ZZ, Wang JQ et al (2015) Three-dimensionally interconnected nickel-antimony intermetallic hollow nanospheres as anode material for high-rate sodium-ion batteries. Nano Energy $16: 389-398$

123. Ji L, Zhou W, Chabot V et al (2015) Reduced graphene oxide/tin-antimony nanocomposites as anode materials for advanced sodium-ion batteries. ACS Appl Mater Interfaces 7(44):24895-24901

124. Han J, Zhu KJ, Liu P et al (2019) N-doped CoSb@C nanofibers as a self-supporting anode for high-performance $\mathrm{K}$-ion and $\mathrm{Na}$ ion batteries. J Mater Chem A 7(44):25268-25273

125. Wang LB, Wang CC, Zhang N et al (2017) High anode performance of in situ formed $\mathrm{Cu}_{2} \mathrm{Sb}$ nanoparticles integrated on $\mathrm{Cu}$ foil via replacement reaction for sodium-ion batteries. ACS Energy Lett 2(1):256-262

126. Liu Q, Yan YW, Chu XC et al (2017) Graphene-induced growth of single crystalline $\mathrm{Sb}_{2} \mathrm{MoO}_{6}$ sheets and their sodium storage performance. J Mater Chem A 5:21328-21333

127. Edison E, Gogoi PK, Zheng Y et al (2019) Electrochemically induced amorphization and unique lithium and sodium storage pathways in $\mathrm{FeSbO}_{4}$ nanocrystals. ACS Appl Mater Interfaces 11(22):20082-20090

128. Zhao YB, Manthiram A (2015) High-capacity, high-rate Bi-Sb alloy anodes for lithium-ion and sodium-ion batteries. Chem Mater 27(8):3096-3101

129. Jiao X, Hu XB, Xi GC et al (2021) $\mathrm{MnSb}_{2} \mathrm{~S}_{4}$ nanorods linked with interconnected reduced graphene oxide as high-performance anode for sodium ion batteries. Electrochim Acta 366:137317

130. Gu HC, Yang LP, Zhang Y et al (2019) Highly reversible alloying/ dealloying behavior of $\mathrm{SnSb}$ nanoparticles incorporated into $\mathrm{N}$-rich porous carbon nanowires for ultra-stable Na storage. Energy Storage Mater 21:203-209

131. Ko YN, Choi SH, Kim H et al (2019) One-pot formation of Sbcarbon microspheres with graphene sheets: potassium-ion storage properties and discharge mechanisms. ACS Appl Mater Interfaces 11(31):27973-27981

132. Liu DY, Yang L, Chen $Z$ et al (2020) Ultra-stable Sb confined into $\mathrm{N}$-doped carbon fibers anodes for high-performance potassium-ion batteries. Sci Bull 65(12):1003-1012

133. Zhao N, Qin J, Chu LJ et al (2020) Heterogeneous interface of Se@ Sb@C boosting potassium storage. Nano Energy 78:105345

134. Cao L, Zhang B, Xia HF et al (2020) Hierarchical chrysanthemum-like $\mathrm{MoS}_{2} / \mathrm{Sb}$ heterostructure encapsulated into N-doped graphene framework for superior potassium-ion storage. Chem Eng J 387:124060

135. Yang L, Hong WW, Tian Y et al (2020) Heteroatom-doped carbon inlaid with $\mathrm{Sb}_{2} \mathrm{X}_{3}(\mathrm{X}=\mathrm{S}, \mathrm{Se})$ nanodots for high-performance potassium-ion batteries. Chem Eng J 385:123838

136. Wang TH, Shen DY, Liu $\mathrm{H}$ et al (2020) $\mathrm{A} \mathrm{Sb}_{2} \mathrm{~S}_{3}$ nanoflower/MXene composite as an anode for potassium-ion batteries. ACS Appl Mater Interfaces 12(52):57907-57915

137. Zhang YF, Li M, Huang FB et al (2020) 3D porous Sb-Co nanocomposites as advanced anodes for sodium-ion batteries and potassium-ion batteries. Appl Surf Sci 499:143907

138. Ding HB, Wang J, Fan L et al (2020) Sn-Sb compounds with novel structure for stable potassium storage. Chem Eng J 395:125147
139. Xiong P, Wu J, Zhou M et al (2020) Bismuth-antimony alloy nanoparticle@ porous carbon nanosheet composite anode for high-performance potassium-ion batteries. ACS Nano 14(1):1018-1026

140. Yang T, Zhong JS, Liu JW et al (2021) A general strategy for antimony-based alloy nanocomposite embedded in Swiss-cheese-like nitrogen-doped porous carbon for energy storage. Adv Funct Mater 31(13):2009433

141. Chen B, Yang L, Bai $X$ et al (2021) Heterostructure engineering of core-shelled Sb@ $\mathrm{Sb}_{2} \mathrm{O}_{3}$ encapsulated in 3D N-doped carbon hollow-spheres for superior sodium/potassium storage. Small 17(6):e2006824

142. Lakshmi V, Mikhaylov AA, Medvedev AG et al (2020) Probing electrochemical reactivity in an $\mathrm{Sb}_{2} \mathrm{~S}_{3}$-containing potassium-ion battery anode: observation of an increased capacity. J Mater Chem A 8(22):11424-11434

143. Zhou L, Cao Z, Zhang J et al (2021) Electrolyte-mediated stabilization of high-capacity micro-sized antimony anodes for potassiumion batteries. Adv Mater 33(8):e2005993

144. Cheng Y, Yao ZP, Zhang QB et al (2020) In situ atomic-scale observation of reversible potassium storage in $\mathrm{Sb}_{2} \mathrm{~S}_{3} @$ carbon nanowire anodes. Adv Funct Mater 30(52):2005417

145. Huang HW, Wang JW, Yang XF et al (2020) Unveiling the advances of nanostructure design for alloy-type potassium-ion battery anodes via in situ TEM. Angewandte Chemie Int Ed 59(34):14504-14510

146. Lu YY, Chen J (2017) Robust self-supported anode by integrating $\mathrm{Sb}_{2} \mathrm{~S}_{3}$ nanoparticles with $\mathrm{S}, \mathrm{N}$-codoped graphene to enhance K-storage performance. Sci China Chem 60(12):1533-1539

147. Yi Z, Qian Y, Tian J et al (2019) Self-templating growth of $\mathrm{Sb}_{2} \mathrm{Se}_{3} @ \mathrm{C}$ microtube: a convention-alloying-type anode material for enhanced K-ion batteries. J Mater Chem A 7:12283-12291

148. Zheng Y, Yong Q, Song J et al (2020) Self-wrinkled graphene as a mechanical buffer: a rational design to boost the K-ion storage performance of $\mathrm{Sb}_{2} \mathrm{Se}_{3}$ nanoparticles. Chem Eng J 379:122352

149. Wu ZB, Liang GM, Pang WK et al (2020) Coupling topological insulator $\mathrm{SnSb}_{2} \mathrm{Te}_{4}$ nanodots with highly doped graphene for highrate energy storage. Adv Mater 32:1905632

150. Luo W, Li F, Zhang WR et al (2019) Encapsulating segmentlike antimony nanorod in hollow carbon tube as long-lifespan, high-rate anodes for rechargeable K-ion batteries. Nano Res 12(5):1025-1031

151. Kim H, Kim JC, Bianchini M et al (2018) Recent progress and perspective in electrode materials for K-ion batteries. Adv Energy Mater 8(9):1702384

152. Pramudita JC, Sehrawat D, Goonetilleke D et al (2017) An initial review of the status of electrode materials for potassium-ion batteries. Adv Energy Mater 7(24):1602911

153. Zhu S, He CN, Zhao NQ et al (2021) Data-driven analysis on thermal effects and temperature changes of lithium-ion battery. J Power Sour 482:228983

154. Xu J, Dou SM, Wang YQ et al (2021) Development of metal and metal-based composites anode materials for potassium-ion batteries. Trans Tianjin Univ 27(3):248-268

155. Zhu S, Zhao NQ, Li JJ et al (2019) Hard-template synthesis of three-dimensional interconnected carbon networks: rational design, hybridization and energy-related applications. Nano Today 29:100796

156. Zhang X, Zhao NQ, He CN (2020) The superior mechanical and physical properties of nanocarbon reinforced bulk composites achieved by architecture design-a review. Prog Mater Sci 113:100672

157. Fan XY, Liu B, Liu J et al (2020) Battery technologies for gridlevel large-scale electrical energy storage. Trans Tianjin Univ 26(2):92-103 

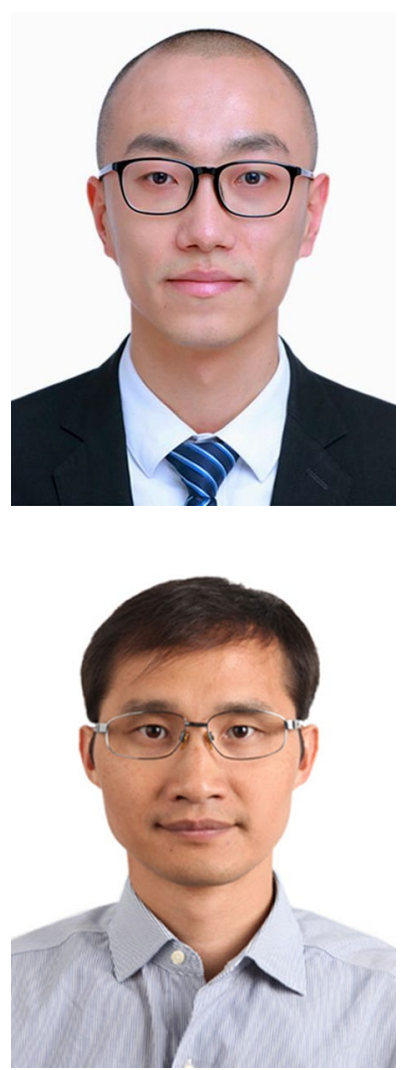

Shan Zhu obtained his Ph.D. from Tianjin University in 2019. Now, he is working as a postdoctoral research fellow in Prof. Naiqin Zhao's group. His research interests include machine learning, nanomaterials, and energy-related applications.

Chunnian He is a full professor in the School of Materials Science and Engineering of Tianjin University. He received his Ph.D. degree from Tianjin University in 2008 and worked as a visiting scholar at the Massachusetts Institute of Technology in 2016. His research interests are the metal matrix composites and the advanced nanomaterials. 